\title{
Regional analysis of domestic integration in Egypt: an interregional CGE approach
}

\author{
Eduardo Amaral Haddad ${ }^{1,2^{*}}$ (1), Michael L. Lahr ${ }^{3}$, Dina N. Elshahawany ${ }^{4}$ and Moisés Vassallo ${ }^{2}$
}

*Correspondence:
ehaddad@usp.br
${ }^{1}$ Department of Economics,
University of Sao Paulo, Av.
Prof. Luciano Gualberto, 908,
FEA I, Cidade Universitária,
São Paulo, SP 05508-900,
Brazil
Full list of author information
is available at the end of the
article

${ }^{*}$ Correspondence: ehaddad@usp.br University of Sao Paulo, Av. Prof. Luciano Gualberto, 908, FEA, Cidade Universitária, Brazil is available at the end of the article

\begin{abstract}
We develop an interregional computable general equilibrium model to help assess the ex ante impact of transportation infrastructure policies in Egypt. The model is integrated with a GIS network. We illustrate the analytical capabilities of the model by looking at the domestic integration of the country. Improvements of transportation costs among Egyptian governorates and of their links to the broader world economy are considered in stylized simulations. The results provide quantitative and qualitative insights (general equilibrium effects) into trade-offs commonly faced by policy makers when dealing with transportation infrastructure projects in a spatial context. In the case of Egypt, there seems to be an important trade-off between efficiency and regional equity: projects that produce potential higher impacts on national GDP also tend to contribute more to regional concentration.
\end{abstract}

Keywords: Impact analysis, Interregional CGE models, Transport infrastructure, Accessibility, Egypt

JEL Classification: R13, R42, C68

\section{Background}

Economic development occurs unevenly across geographic space. Indeed, almost all nations can identify both more-developed and less-developed regions. Egypt is no exception: it is characterized by a high concentration of production factors and resources in governorates comprising the greater Nile delta-Lower Egypt. These concentrations parallel and perhaps even cause the nation's uneven distribution of wealth and population across regions. The interregional wealth disparity crops up in the form of other socio-economic conditions, ranging from health and education to labor market conditions (World Bank 2012).

Interest by policymakers on regional issues within Egypt has been recently renewed with the publication of the World Bank (2012) report Reshaping Egypt's Economic Geography: Domestic Integration as a Development Platform. It investigates Egypt's regional economic growth, explores the causes for geographically unbalanced development, and proposes policy options to make unbalanced growth compatible with inclusive development. Spatially connective infrastructure is a primary pillar for future policies to address the country's spatial disparities. In a context of growing global integration and increasing 
international competition, new challenges are likely to emerge in Egypt's regional economies. It is hoped that they may be partially addressed via integration of the nation's economic periphery and core. One way to better integrate the nation is to improve its transportation network.

This paper focuses on the potential regional impacts of domestic integration on regional inequality in Egypt. It looks not only at the domestic integration of the country by improving links among regions' domestic demanders and suppliers, but also by improving the nation's links to the broader world economy.

The Egyptian economy is not internally homogenous. It presents variations across both industries and regions. Thus, it is expected that the impact of economic policies will vary across different governorates (mohaafazaat). In the context of renewed attention to the spatial aspects of economic development, both from a theoretical perspective (Fujita and Krugman 2004) and from a policy perspective (World Bank 2009), there is a growing need for economic and socio-economic models that could provide new insights into the nation's regional planning process.

In this paper, we develop one such tool: an interregional computable general equilibrium (ICGE) model for Egypt. The work is based on previous work by Haddad (1999), Lahr (2001), Haddad and Hewings (2005), Álvarez-Martínez and Lahr (2013) and Haddad (2014a, b). The consequent model is developed with an eye toward gaining added insight to the ex ante assessment of domestic integration policies in the country. As highlighted in Haddad et al. (2011a, p. 45), modeling of transportation costs provides an important way of dealing explicitly with theoretical issues related to integrated regional systems. The explicit modeling of transportation costs in the ICGE model, which is based on origindestination flows, organically will take into account the spatial structure of the Egyptian economy. That is, the ICGE model is integrated with a stylized geo-coded transportation network model, thereby augmenting the general model framework for understanding the role of infrastructure investment in regional economic development. There are important proposals of infrastructure projects contemplated in the Egyptian government's five-year plan-such as the Cairo-Asyout road improvement, the Suhag-Red Sea improvement, and the Cairo Ring Road improvement. For the sake of future fiscal and policy decisions, their ex ante impacts ought to be assessed (Felkner et al. 2012).

To examine possible spatial effects of transportation cost reductions in Egypt induced by transportation infrastructure improvements, we adopt a cost-competitiveness approach. It reviews possible relative changes in the regional costs and on different demand structures. Following Haddad et al. (2011), we scrutinize the link between the freeness of trade and the equilibrium distribution of activities. It is clear from many prior studies (Yang and Lahr 2008; Aroca et al. 2008; $\mathrm{Hu}$ and McAleer 2004) that domestic economic integration is effected by reducing transportation costs. There is no reason to expect this should not be the case among Egyptian regions. For our model, we adopt a broad concept of market access and supplier areas that includes both domestic and foreign trade. To calibrate the ICGE model, we employ a fully specified interregional input-output system that includes commodity flows across Egypt's regions as well as to the rest of the world. Moreover, we allow labor and capital to be mobile; this also spurs interregional integration.

In what follows, Sect. 2 introduces the main features of the ICGE model. Section 3 is a discussion of the details of how we modeled transportation costs and integrated the 
ICGE model via a stylized network using GIS techniques. In Sects. 4 and 5, we design and simulate two experiments and discuss the main results. Final remarks follow in an attempt to evaluate our findings and put them into perspective, considering their extension and limitations.

\section{The ICGE model ${ }^{1}$}

We develop an ICGE model for Egypt. ${ }^{2}$ Drawing on recent experience reported in Haddad (2014a, b) in the development of an ICGE model for Lebanon under conditions of limited information, we develop the interregional structure of the model. ${ }^{3}$ Incorporating the ability to model transportation costs changes that explicitly affect interregional relationships enables investigations into important issues related to integrated regional systems. The model developed in this paper is designed for analyzing policies related to changes in Egypt's existing transportation infrastructure.

Our model has $R$ endogenous regions, $r=1, \ldots, R$, and one exogenous region (the rest of the world), $R O W$, that exhaust Egypt's space economy. Economic interactions take place inside (intraregional trade) and outside the endogenous regions (interregional and international trade). The regional setting of the model recognizes the economies of $R=27$ Egyptian governorates (mohaafazaat) (Fig. 1).

Agents' behavior is modeled at the regional level, accommodating variations in the structure of regional economies. An important feature of the model is the detailed treatment of interregional trade flows in the Egyptian economy, in which interregional commodity flows are fully specified by origin and destination. The building blocks of the "structural" components of the ICGE model are very standard in their specifications. ${ }^{4}$ Results are based on a bottom-up approach-i.e. national results are aggregates (sums) of the individual regional results. The model identifies nine production/investment sectors in each region producing nine commodities (Table 1), one representative household in each region, one government in each region, and a single foreign area that trades with each domestic region. ${ }^{5}$ Each industry uses two local primary factors (capital and labor) to produce along with regional material endowments. Special groups of equations define capital accumulation relations.

The model is structurally calibrated for 2011. A rather complete dataset for Egypt is available for 2011-the year of the national input-output accounts used to the estimate of the interregional input-output database. Additional structural data for 2007-2011 complement that database.

Our model is a Johansen-type model. That is, solutions are obtained by solving the system of linearized equations of the model following the Australian tradition. A typical result shows the percentage change in the set of endogenous variables, after a policy is carried out, compared to their values in the absence of such policy, in a given environment. The schematic presentation of Johansen solutions for such models is standard in the literature. More details can be found in Dixon and Parmenter (1996).

\footnotetext{
${ }^{1}$ This section draws on Haddad (2014a).

2 To our knowledge, this is the first fully operational ICGE for Egypt.

${ }^{3}$ See also Peter et al. (1996), Haddad (1999), and Haddad and Hewings (2005).

${ }^{4}$ Peter et al. (1996) and Haddad (1999).

${ }^{5}$ The domination in Egypt of Mediterranean ports makes the latter a fairly realistic assumption.
} 


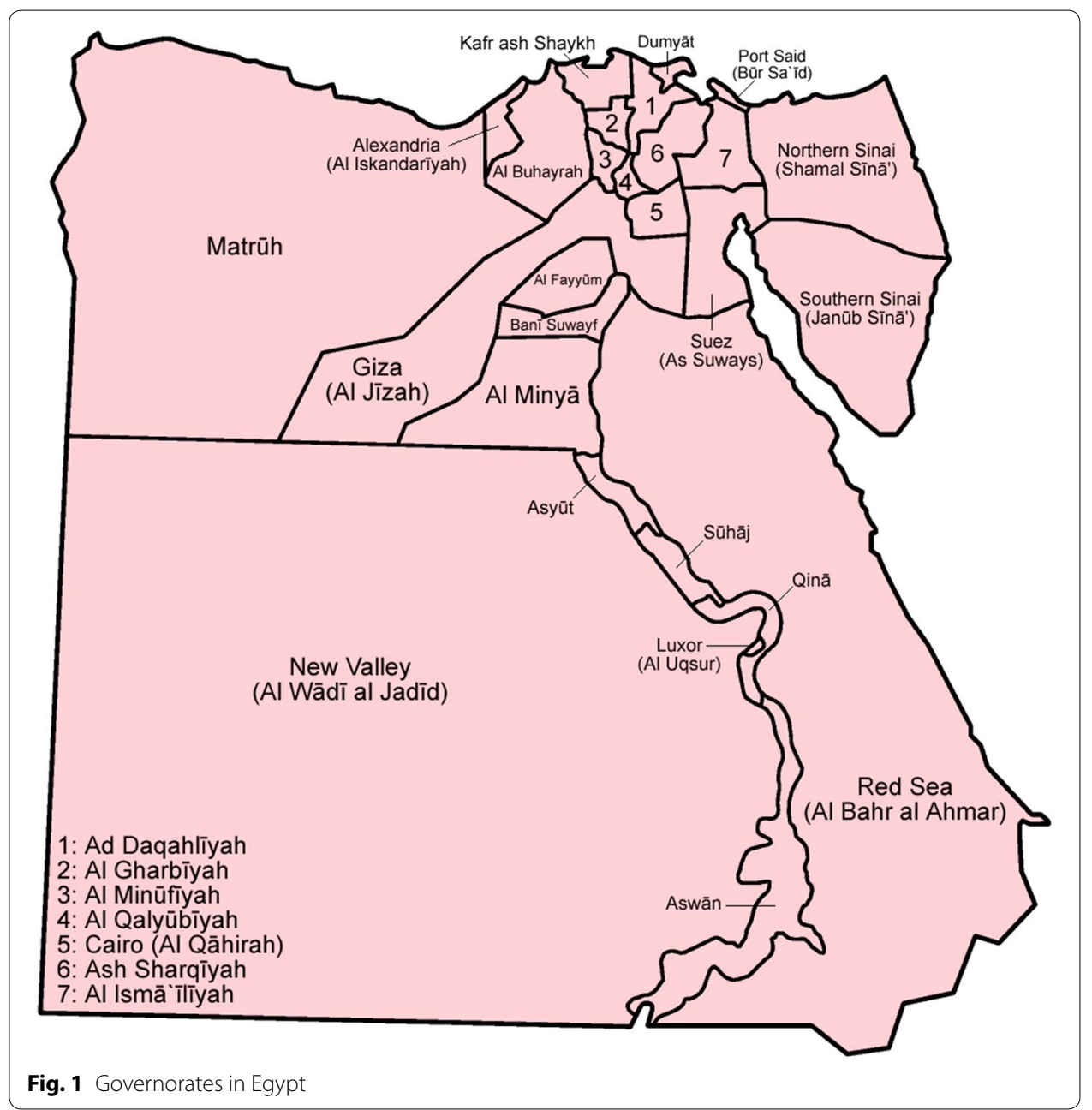

\subsection{Overview}

The basic structure of the ICGE model is standard; it is comprised of three main blocks of equations that determine both supply and demand relations as well as market clearing conditions. In addition, various regional and national aggregates, such as aggregate employment, aggregate price levels, and balance of trade, are defined. Nested production functions and nested household demand functions are employed.

\section{Table 1 Sectors/products in the ICGE model}

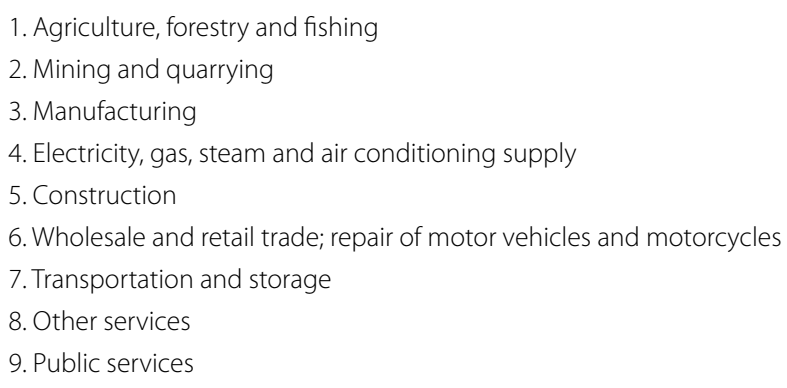




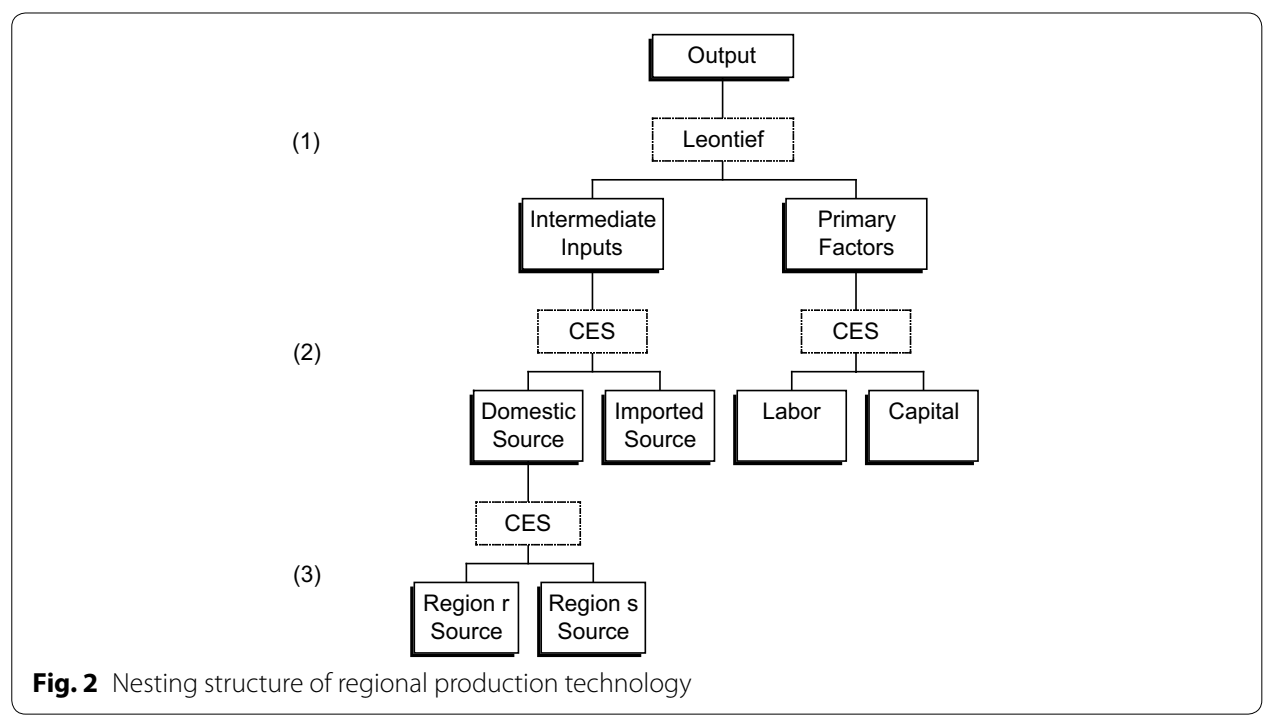

Figure 2 illustrates the basic production technology adopted in the model, which is a common specification in regional models. Dotted-line boxes identify the functional forms used at each level of the model hierarchy. Two broad categories of inputs are recognized: intermediate inputs and primary factors. Producers in each regional industry choose input requirements per unit of output through optimizing behavior (cost minimization). The nested production Leontief/CES technology requirements constrain production levels. Leontief technology assures that firms use intermediate inputs in fixed proportion to the combined set of production factors (labor and capital) at the first level, but at a second level the two factors can substitute for each other as can domestically produced and imported intermediate inputs. At the third level, domestically produced inputs are cost-based bundled combinations of inputs from the nation's different regions.

The treatment of the household demand structure is based on a nested CES/linear expenditure system (LES) preference function (Fig. 3). Demand equations are derived

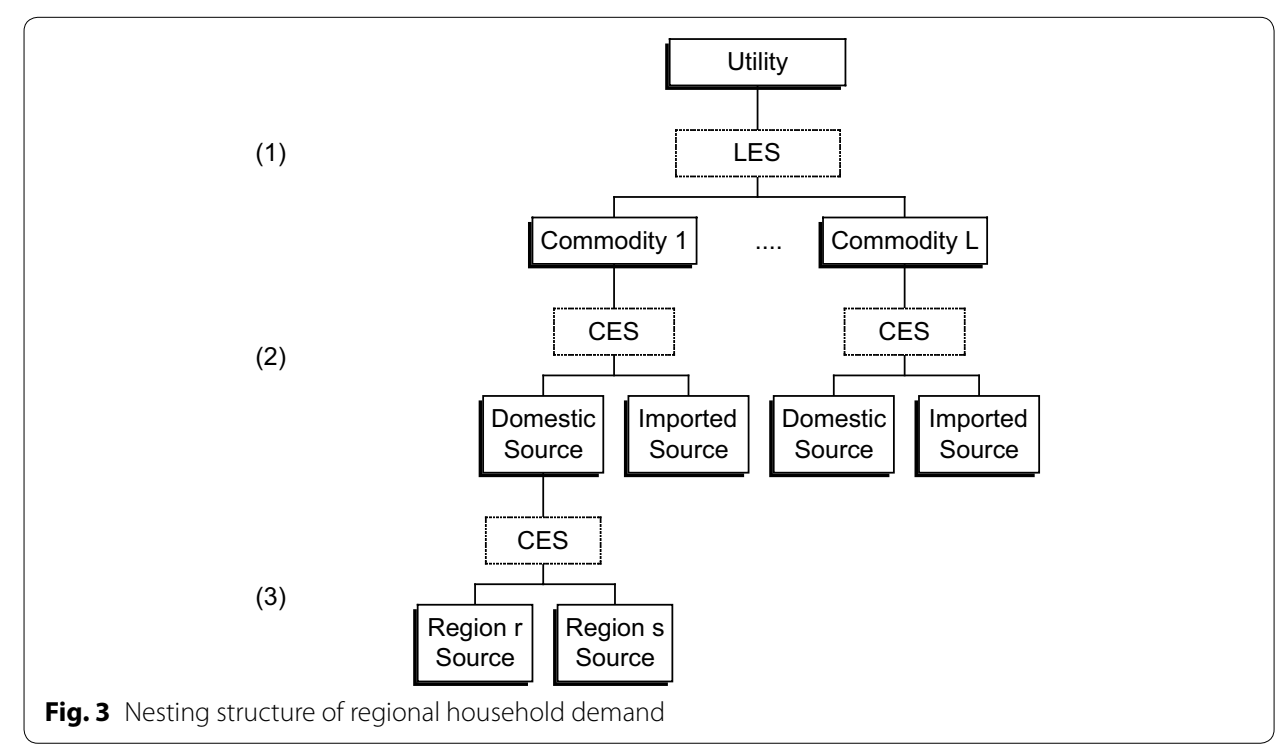


from a Stone-Geary utility maximization problem, the solution of which follows hierarchical steps. The structure of household demand follows a nesting pattern that enables different elasticities of substitution to be used. At the bottom level, substitution occurs across different domestic sources of supply. Utility derived from the consumption of domestic composite goods is maximized. In the subsequent upper level, substitution occurs between domestic composite and imported goods.

Equations for other components of final demand for commodities include the specification of export demand and government demand. Exports face downward-sloping demand curves, indicating a negative relationship with their prices in the world market.

The nature of the input-output data enables the isolation of the goods supplied by the government-whose demand follows changes in tax revenues. However, "productive" activities carried out by the public sector cannot be isolated from those by the private sector. Thus, government entrepreneurial behavior is dictated by the same cost minimization assumptions applied to the private sector.

An important feature of the ICGE model is the ability to explicit model the costs of moving products based on origin-destination pairs according to the allocation of trade margins. The model is calibrated taking into account the specific trade cost structure of each commodity flow. Such structure is physically constrained by the available transportation network, modeled in a stylized geo-coded transportation module (see Sect. 3).

Other definitions in the ICGE core module include: basic and purchaser prices of commodities, components of real and nominal GRP/GDP, regional and national price indices, money wage settings, factor prices, employment aggregates, and capital accumulation relations. $^{6}$

\subsection{Structural database}

The ICGE database requires detailed sectoral and regional information about the Egyptian economy. An interregional input-output system for Egypt is used in the process of calibration of the structural coefficients of the model. Recent efforts in the construction and improvement of such database are currently under way as part of an initiative involving researchers from the Regional and Urban Economics Lab at the University of São Paulo (NEREUS), the Rutgers Economic Advisory Service (R/ECON) at the Edward J. Bloustein School of Planning and Public Policy at Rutgers University, and the Faculty of Commerce at the Zagazig University. A fully specified interregional input-output database has been estimated under conditions of limited information. The development of the input-output system relied basically on the following databases: (1) aggregate input-output table for year 2010/2011 at basic prices; (2) Household Income, Expenditure, and Consumption Survey, HIECS 2010/2011; (3) sectoral employment data, by governorate; (4) other socio-economic indicators by governorate; and (5) estimated travel time among governorates' capitals. ${ }^{7}$ Summary indicators of the database are presented in Tables 2 and 3.

\footnotetext{
${ }^{6}$ The core system of equations of the model is available in the "Appendix".

${ }^{7}$ More details on the procedures adopted can be found in Haddad (2014b), who describes a similar approach for Lebanon.
} 


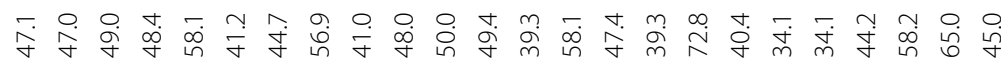

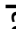

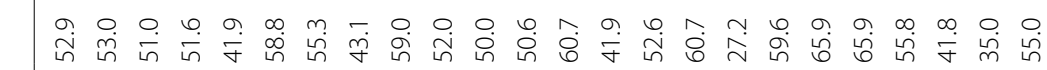

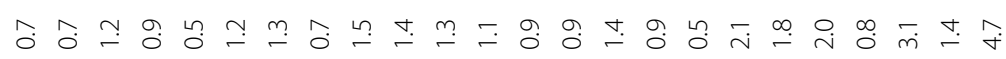

(

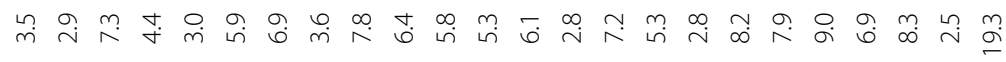

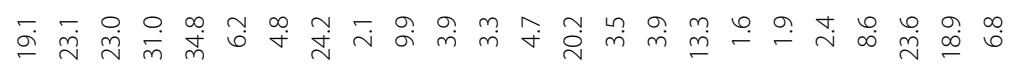

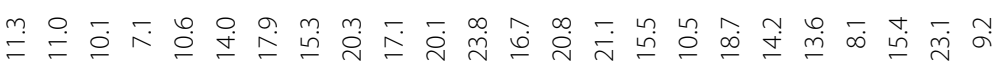

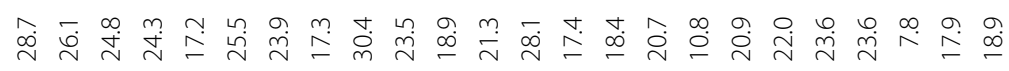

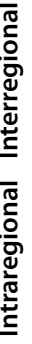

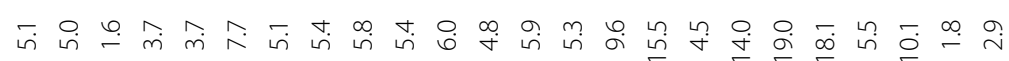

它导芒

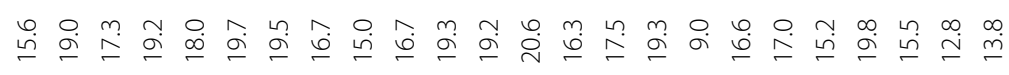

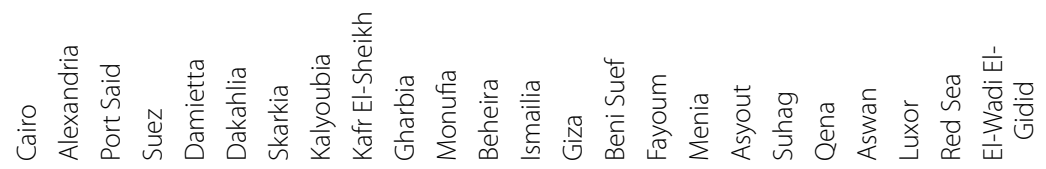

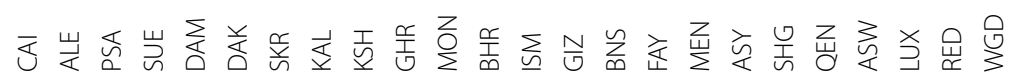

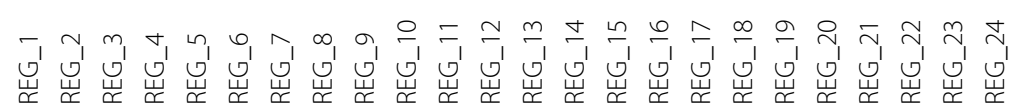




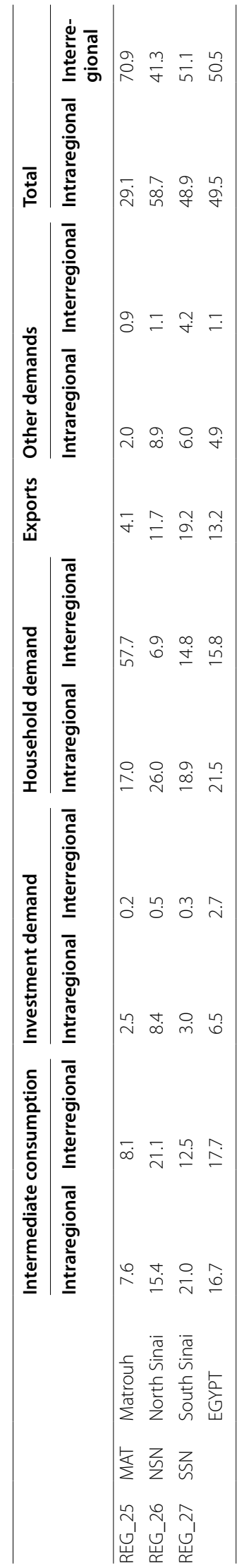




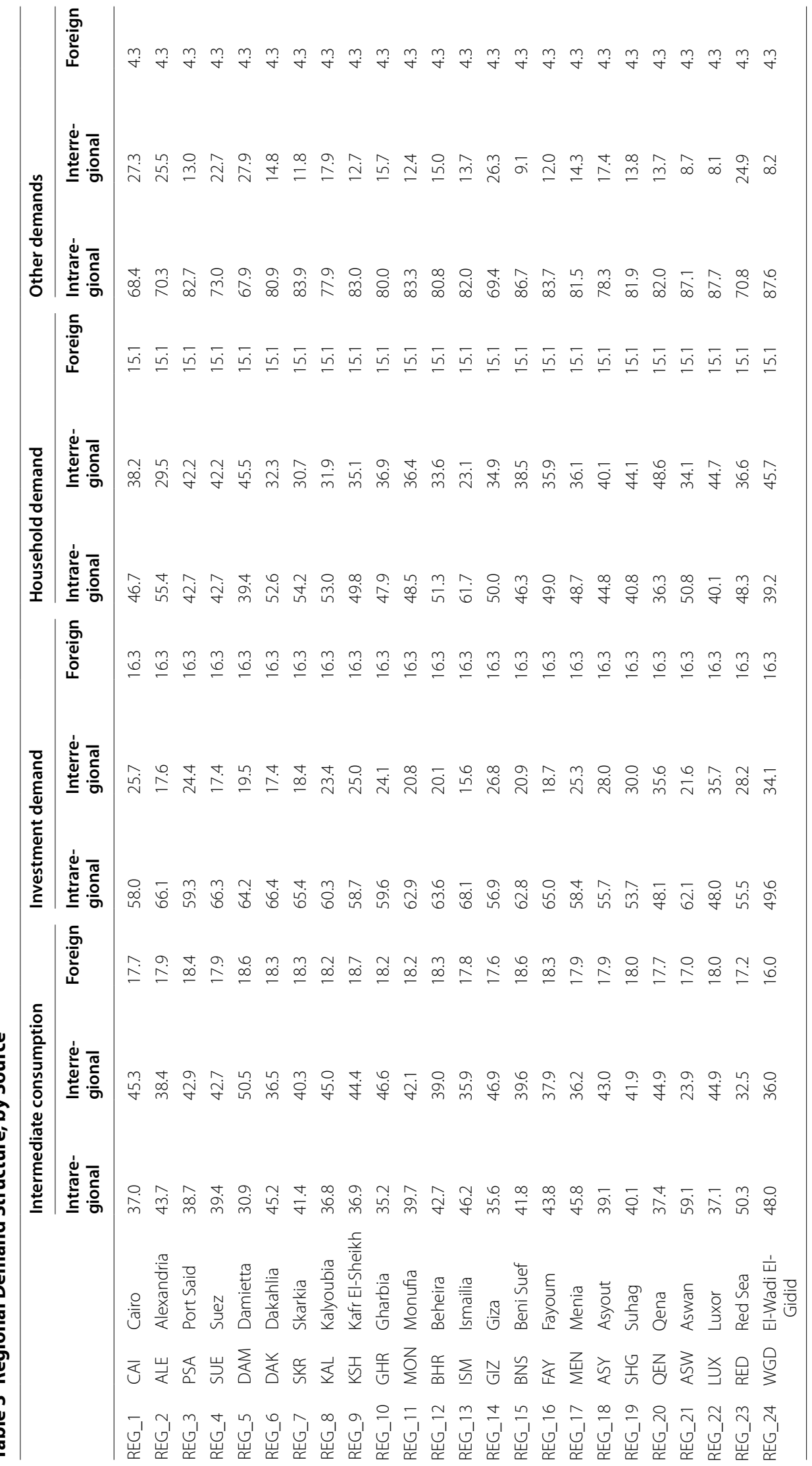




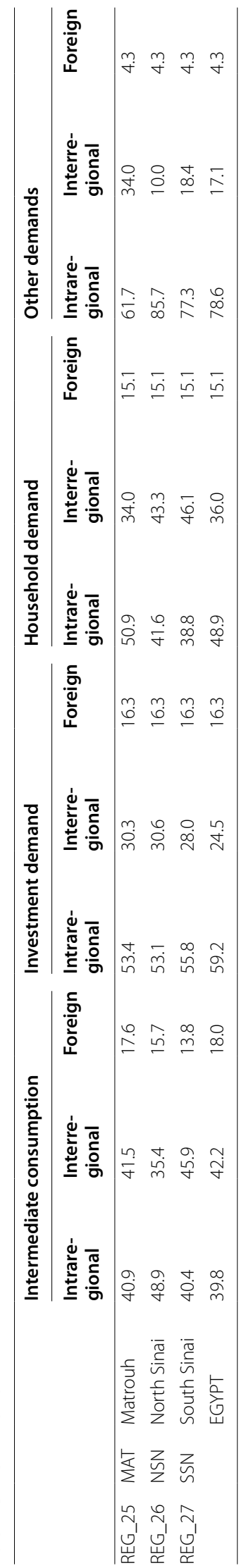




\subsection{Behavioral parameters}

As is unfortunately typical, direct empirical estimates of the key parameters of the model are not readily available. We thus were forced to rely on estimates from existing studies, where pertinent and available, or on "best guesstimates" based on typical values used in similar models for developing nations. In the case of ICGE models, the degree of interregional interaction of all markets includes different dimensions. One possible dimension of "openness" of regional economies is encompassed in the elasticities of substitution between similar commodities produced in different regions. A common assumption widely used in interregional CGE models, the Armington assumption, considers similar commodities produced in different regions as close substitutes, but unique goods. It allows for the incorporation of estimates of elasticities of substitution between domestically produced products and similar imported products, and between regionally produced products and similar products from other regions, suggesting nested multiple stage demand functions. Spencer (1988) points out that this assumption is extraordinarily convenient for (interregional) CGE work, since it admits the presence of cross hauling in a standard neoclassical model and reduces concern about small changes having big effects on the pattern of trade and production (ruling out specialization in consumption). However, econometric estimates for such elasticities for interregional substitution are extremely rare, and modelers often have to extrapolate from estimates for their equivalent parameters for substitution between domestic and foreign commodities. In our model, parameter values for international trade elasticities, $\sigma$ 's in Eq. (2) in the "Appendix", were set to $1.5 ;^{8}$ regional trade elasticities, $\sigma$ 's in Eq. (1), were set at the same values as the corresponding international trade elasticities.

Substitution elasticity between primary factors, $\sigma$ 's in Eq. (3), was set to 0.5 . The marginal budget share in regional household consumption, $\beta$ 's in Eq. (5), was calibrated from the input-output data, assuming the average budget share to be equal to the marginal budget share. We have set to -2.0 the export demand elasticities, $\eta$ 's in Eq. (7).

\subsection{Closure rules}

To capture the effects of regional integration, the simulations are carried out using both short- and long-run closure rules. ${ }^{9}$ The model has no dynamic attributes. Thus, any simulations run using the ICGE model capture the effects associated with a static impacteffect question, i.e., given the structure of the economy, what-if questions are addressed in a comparative static framework. Short- and long-run considerations differ in the way the equilibrating mechanisms are set through specified closure rules. Structural changes are captured only by evaluating the re-allocation of resources.

\footnotetext{
${ }^{8}$ Eby Konan and Maskus (1996) used the value 2.0 for such parameter in their study on trade liberalization scenarios for Egypt; based on that, Hendy and Zaki (2013) adopted the same value in their CGE model to analyze a $10 \%$ tariff cut in Egyptian imports.

9 The system of equations provides the theoretical structure of the model. In the implementation of the ICGE model, the linearized version of the model was condensed by eliminating some equations and variables, generating a reduced version with 24,443 equations and 43,376 variables. To close the model, values for 18,933 variables-usually technicalchange variables-have to be set exogenously (the number of endogenous variables must equal the number of equations). The condensation procedure, i.e., the reduction of the size of the model, is carried out by substituting out variables that are to be endogenous and are of less interest to the analysis and presentation of the simulation results, and by omitting variables that are to be exogenous and not shocked in the simulations. The nominal exchange rate was set as the numéraire.
} 
Giesecke and Madden (2013) point that, in comparative static applications, modeling of the labor market, particularly as it relates to wages and employment flexibility, is one of the ways in which short-run and long-run analytical timeframes are commonly distinguished. In short-run applications-the authors go on-a common assumption is that institutional or structural features of the regional labor market generate short-run stickness in the regional wage rate. With sticky short-run regional wages, regional labor market pressures are mainly expressed as movements in shortrun regional employment. With short-run regional populations given, these shortrun regional employment movements are expressed as short-run movements in the regional employment rate and/or participation rate. In our model, the short-run closure assumes fixed regional population and labor supply, fixed regional wage differentials, and fixed national real wages. Regional employment is driven by the assumptions on wage rates, which indirectly determine regional unemployment rates. Labor is, thus, mobile only across sectors within the same region. In the implementation of the long-run closure of the model, aggregate employment is determined by fixed population change, fixed labor force participation rates, and the "natural" unemployment rate (the unemployment rate at the start of the simulation). The distribution of labor across regions and sectors is subsequently endogenously determined. It is assumed that interregional wage relativities are exogenous. As observed by Giesecke and Madden (2013), this translates to near exogeneity of the regional labor wage rate, with longrun regional employment adjusting via long-run movements in regional populations. Labor is thus attracted to more competitive industries and regions. In essence, population movements (i.e., interregional migration) keep overall household utility differentials constant.

Another important distinction between short- and long-run closures relates to the treatment of the supply side of regional industry capital markets. In short-run closure, capital stock is fixed, while, in the long-run, policy changes can affect the capital stock. In the long-run, industry "re-location" becomes relevant since factors of production are assumed to be free to move among the regions. Investment decisions define the marginal re-location of activities, guiding the spatial distribution of capital stocks. Regional industry capital stocks adjust to move regional industry rates of return to the exogenously determined benchmark rate of return. Capital is pulled toward more profitable industries, which causes interregional rates of return to converge.

On the demand side, investment expenditures are fixed in the short run-firms cannot reevaluate their investment decisions in the short run. Household consumption follows household disposable income, and real government consumption, at both regional and central levels, is fixed. Trade balance adjusts to accommodate changes in government deficit. In the long-run, movements in the components of trade balance (i.e., exports and imports) are reflected in the hypothesis of fixed share of trade balance in GDP. The government deficit is set exogenously, so that government expenditures can change in the margin, moving with changes in the endogenously determined changes in government revenues. Domestic absorption has to accommodate the balance of trade constraint. 


\section{Integration of the ICGE and the transportation network module}

A main goal of the research reported in this paper is to develop a framework to enable assessment of the socio-economic impacts of domestic integration policies in Egypt. As proposed in Haddad and Hewings (2005), we integrate a geo-coded transportation network for Egypt with the ICGE model (Fig. 4). Thus, if one wants to simulate changes in the network, which might affect relative accessibility (e.g., road improvements, investments in new highways, etc.), a transportation cost matrix can be calculated ex ante and ex post, and mapped to the ICGE model through transportation cost functions. This mapping includes two stages, one associated with the calibration phase, and another with the simulation phase.

Following Haddad and Hewings (2005), the set of equations that specify purchasers' prices in the ICGE model imposes zero pure profits in the distribution of commodities to different users. Prices paid for commodity $i$ from source $s$ in region $q$ by each user equate to the sum of its basic value and the transportation costs associated with the use of the relevant margin-commodity.

The role of the margin-commodity is to facilitate flows of commodities from points of production or points of entry to either domestic users or ports of exit. The margin-commodity, or, simply, margin, includes transportation services. Combined, they take account of transfer costs in a broad sense. ${ }^{10}$ The margin demand equations in the model show that the demands for margins are proportional to the commodity flows with which the margins are associated; moreover, a technology change component allows changes in the implicit transportation rate. ${ }^{11}$

The model uses a general functional form for the equations of margin demand, for different users. Let $x$ be a flow of some good $i$ from some region $s$ to region $r$, and $m$ the quantity of the required transportation margin. ${ }^{12}$ Assuming $m=A \eta x$, with parameter $\eta$ specific to $i, s$ and $r$, and $A$, specific to $i, s$ and $r$, being a shift variable used to rescale the reference estimates of $\eta$. Thus, an integration scenario, reducing transportation costs from region $s$ to region $r$ by say $10 \%$, is modeled by reducing $A$ by $10 \%$ for all goods $i .^{13}$

We use a stylized national-level road network data in a GIS setting obtained from the Egyptian Central Agency for Public Mobilization and Statistics (CAPMAS). We merged this database with information on specific technical attributes of the links provided, namely the maximum speed according to the type of road. In the ICGE model, it is assumed that the locus of production and consumption in each governorate is located in its capital; international trade is assumed to occur only through the Alexandria port. Thus, the relevant travel times associated with the flows of commodities from points of production (or port of entry) to points of consumption (or port of exit) are limited to a matrix of times between governorate capitals. Moreover, to account for interregional

\footnotetext{
${ }^{10}$ Hereafter, transportation services and margins will be used interchangeably.

11 In the case of international imported goods, the implicit transportation margin is interpreted as the costs at the port of entry plus land transportation costs to the consuming region, while for foreign exports it includes transportation costs from the producing region and the costs at the port of exit.

12 Similarly, one can think about flows of exports from the producing region to the port, or flows of imports from the port to the consuming region.

13 The process of calibration of transportation costs assumes $A=1$ for all $i, s$ and $r$ in the benchmark year. Thus, $\eta$ can be calibrated by calculating the relationship between $m$ and $x$ directly from the interregional input-output database.
} 


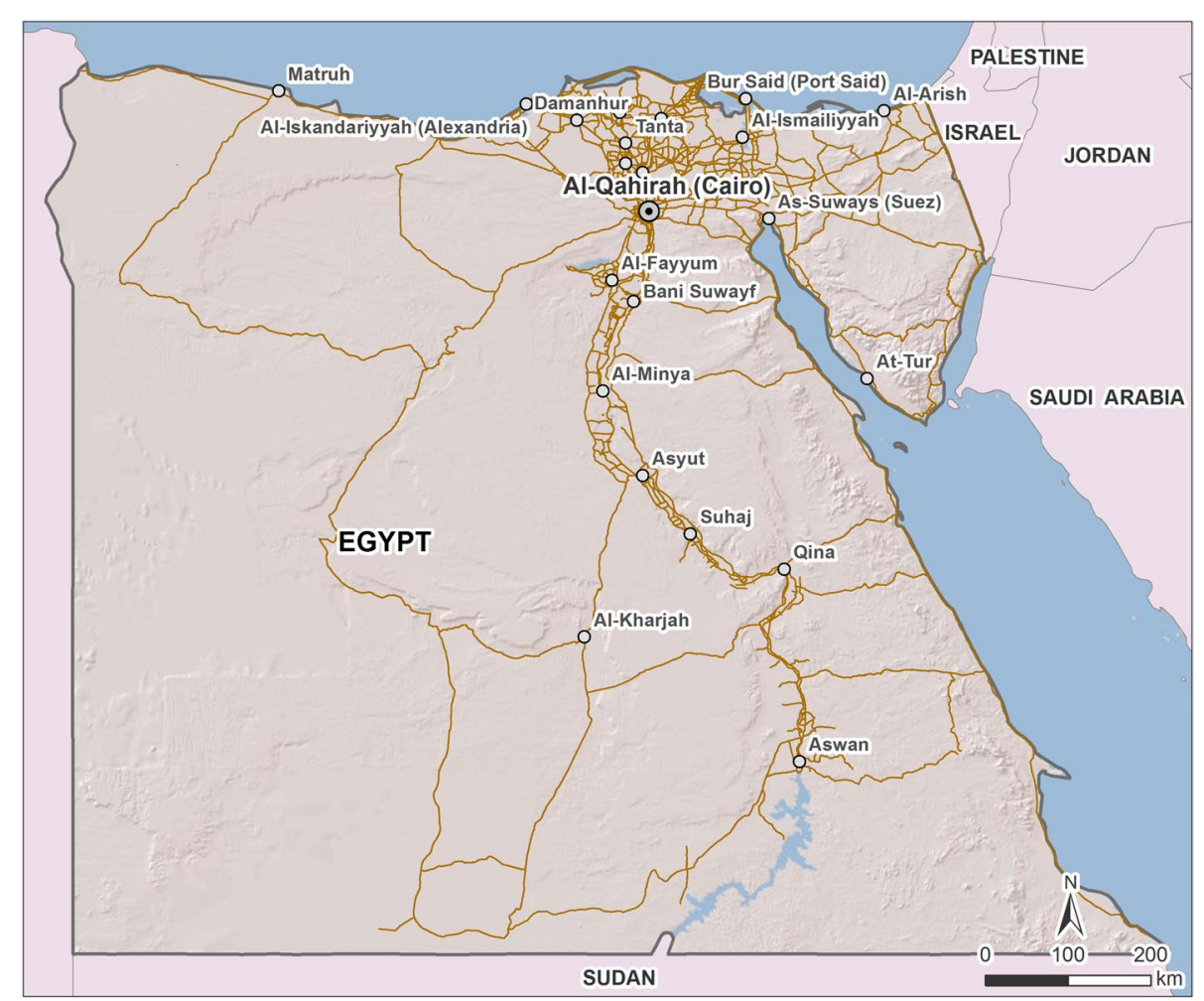

Fig. 4 Transportation network for Egypt

transportation costs, we let trade within the governorate take place on an abstract route between the capital and a point located at a distance equal to half the minimum time from capital cities of all adjacent governorates. The transportation module calculates the minimum interregional times, considering the existing road network. ${ }^{14}$

Calibrating the ICGE model requires information on the transportation margins related to each commodity flow. Aggregate information for margins on intersectoral transactions, capital creation, household consumption, and exports are available at the national level. Thus, disaggregating this information for commodity flows across governorates to generate interregional input-output accounts of Egypt was somewhat problematic. ${ }^{15}$ Travel times were then associated with the transportation costs implicit in the flows in ICGE social accounting matrix by assuming tariff functions using data on general cargo prices (for domestic trade flows) and container prices (for international trade flows) from a survey conducted in Felkner et al. (2012). We used a gravity model formulation with the general functional form: $\operatorname{tariff}_{i}=\alpha_{i} * \operatorname{time}^{\beta_{i}}$, where tariff ${ }_{i}$ is the road transportation price for shipment $i, i=$ general cargo, container; and time refers to the minimum travel distance between two governorate capitals. Long-haul economies are shown in Table 4, which presents the estimates of the parameters for the two functions.

For each origin-destination pair, such a calibration strategy explicitly accounts for key elements of Egypt's integrated interregional economic system, namely: (a) the type of

\footnotetext{
14 According to the Ministry of Transport of Egypt, $94 \%$ of the nation's freight is transported by road (http://www. comcec.org/).

15 This procedure was first documented in Haddad and Hewings (2005).
} 
Table 4 Estimated road transport cost functions-general cargo and container

\begin{tabular}{lllll}
\hline Variable & Coefficient & SE & t-Statistic & Prob. \\
\hline Dependent variable: Icargocost & 0.65914 & & & \\
Ltime & 0.53872 & 0.03852 & 17.11 & 0.000 \\
Constant & 0.8443 & 0.21313 & 2.53 & 0.014 \\
$R^{2}$ & 56 & & & \\
$N$ & 0.71851 & & & 0.000 \\
Dependent variable: Icont & 0.02769 & 25.95 & 0.000 \\
Ltime & 3.65506 & 0.15317 & 23.86 & \\
Constant & 0.9258 & & & \\
$R^{2}$ & 56 & & & \\
$N$ &
\end{tabular}

Obs.: Icargocost log of price per ton, Icont log of price of container, Itime log of travel time

trade involved (transportation costs vary according to specific commodity flows); (b) the actual travel time on the current transportation network (distance and time matters); and (c) scale effects in transportation in the form of long-haul economies.

\section{Analytically important transportation links}

In this section, we look at the issue of structural sensitivity analysis in CGE models. We borrow from the field of influence literature (Sonis and Hewings 1989, 1992) the idea of inverse important coefficients in order to identify strategic transportation links in the context of the Egyptian interregional system. ${ }^{16}$ Given the nature of CGE models, we can also expand the concept of measurement of the field of influence statistics in order to generate qualitative structures of influences based on different policy targets.

In order to identify the analytically most important structural links, we proceed with a thorough decomposition of the results of simulations that consider the role of small changes in transportation costs. These incremental changes are associated with (a group of) coefficient changes computed from the information contained in the initial solution. In essence, they are elasticities. In other words, we can identify the elasticity of the model's overall findings to changes effected upon specific transportation links. ${ }^{17}$ In summary, fields of influence of various structural links can be associated with specific policy outcomes.

For each pair of regions, we calculate the contribution of (small) changes in transportation costs to specific outcomes, considering different dimensions of regional policy. We look at the effects on national GDP and national real household consumption. While GDP effects attempt to measure systemic efficiency, we use changes in real household consumption as a simple index of welfare. Moreover, we also consider impacts on regional efficiency, through the differential impacts on GRP for the seven Egyptian macroregions (Greater Cairo, Alexandria, Asyout, Delta, North Upper Egypt, Suez, and South Upper Egypt). The spatial results are staged in order to evaluate the extent to which analytically important links optimize specific policy goals.

\footnotetext{
${ }^{16}$ Haddad and Hewings (2007) show the mathematical equivalence of the structures of CGE models of the Johansen class, and of input-output models.

17 This approach allows considering the two-way dimension of a transportation link between any two regions, i.e. the way "in" and the way "out".
} 
The basic experiment consists of evaluating an overall $1 \%$ reduction in transportation cost within the country and with external markets. In other words, for every domestic origin-destination pair, the use of transportation margins is reduced by $1 \%$; in addition, transportation margins related to international trade flows (both foreign imports and exports) are also reduced by $1 \%$. The simulations are carried out under both shortand long-run environments to obtain a sense of outcome sensitivity to the different closure rules. In this vein, we are able to assess potential efficiency and welfare gains to the Egyptian economy associated with domestic integration issues, i.e., increases in the freeness of trade, in the context of increasing competition within the country.

To obtain a finer perspective on the analytically most important links for optimizing a given policy target (regional/national efficiency and national welfare), we decompose the results into "governorate to governorate," "governorate to foreign region," and "foreign region to governorate" links. Key links (top 50) based on their influence on each policy target are highlighted in Figs. 5, 6 and 7.

Figure 5 presents the short- and long-run results for national GDP and national welfare. Higher contributions to national GDP in the short run are mainly associated with transportation cost reductions within governorates (intraregional) located in the Lower Egypt; overall better access to imports; better access from governorates in the Lower Egypt to Cairo; and lower transportation costs for exports from the Greater Cairo region. In the long run, a similar pattern emerges. The main difference is that higher contributions for GDP growth arise also from reductions in transportation costs between governorates in the Lower Egypt and the North Upper Egypt, where production of Sector 2 (mining and quarrying) is concentrated, playing an important role in the structure of interindustry linkages and capital creation (especially Menia). Furthermore, better access to imports by some of the governorates becomes less important.

Focusing on the top five links, the higher contributions to national GDP are associated with a better access from Giza to Cairo, as well as a better access to foreign imports for some of the governorates throughout the country (Cairo, Giza, Sharkia, and Qena). In the long run, the top five links contribute with $40.1 \%$ of the total GDP effect (27.7\% in the short run); they are associated with transportation cost reductions within the Greater Cairo region (Cairo-Cairo, Cairo-Giza, and Giza-Cairo links) and better access to imports by Cairo and Menia.

In terms of the contributions to welfare, the main links in the long run are almost the same as those verified for GDP. There is a slight difference in the short run, however, when compared to the GDP analysis: some important links appear to be associated with better access of governorates in the Upper Egypt (Asyout, Suhag, Qena, and Aswan) to local and regional markets.

Figures 6 and 7 present the results for the key links based on their influence on real GRP in the different Egyptian macroregions. Notice that the set of most influential transportation links varies according to different (regional) policy targets. For instance, in the short run, GRP effects in the Greater Cairo region related with domestic integration seem to be more influenced by improved access to domestic suppliers for the governorates that compose the region (Cairo, Giza, and Kalyoubia), as well as better access to foreign markets (imports and exports). This seems to be the pattern for all the regions: a more supplier-oriented access in 


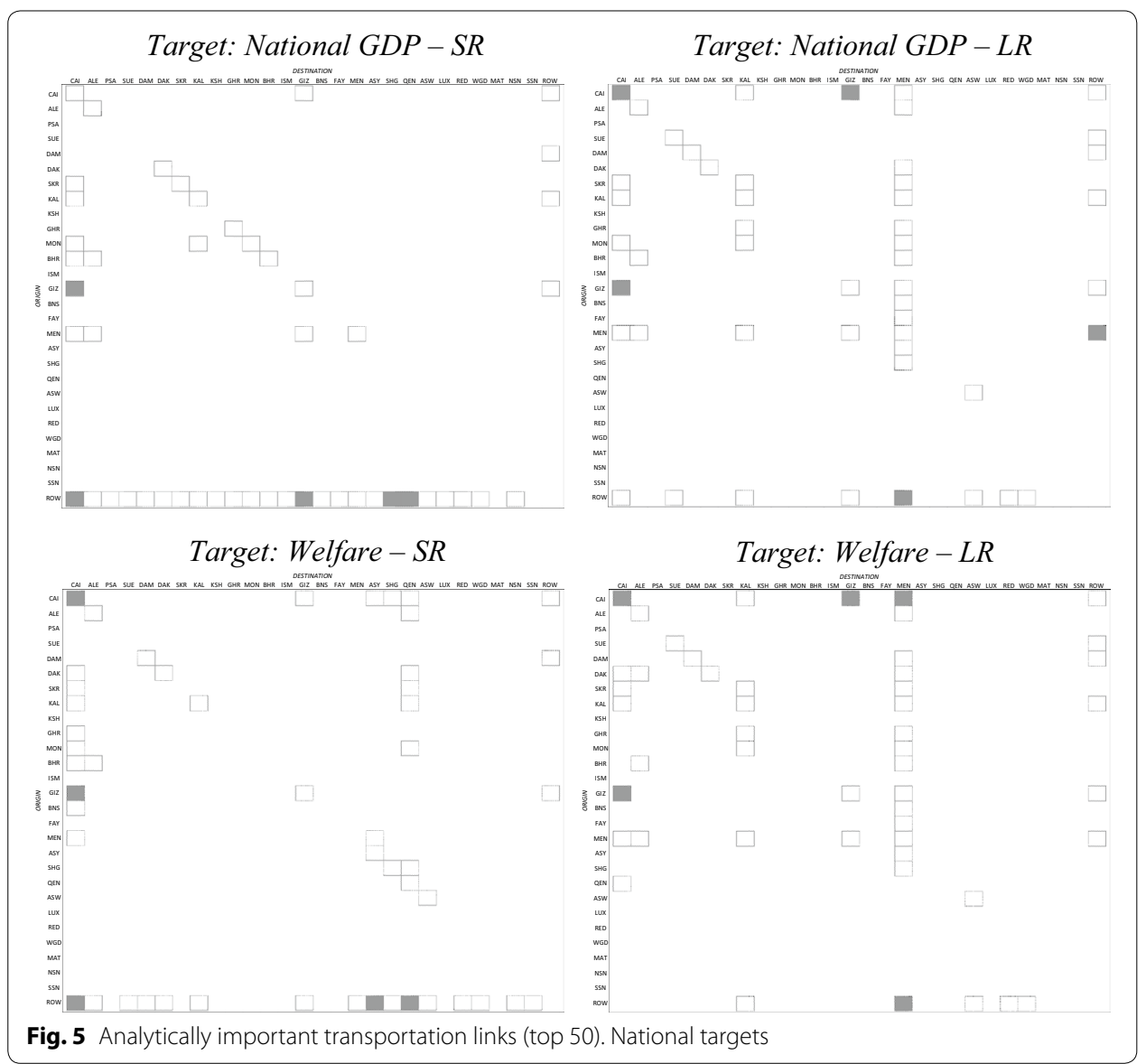

the domestic markets for the governorates in the region, with improved domestic backward linkages, and both market and supplier-oriented access to foreign markets.

In the long run, macroregions in general tend to be relatively more (positively) affected by transportation cost reductions in the Lower Egypt, as well as improvements in the intermediate-good-producing regions in the North Upper Egypt region. The differences in terms of the sets of most influential transportation links related to the different regional policy targets refer to the inclusion of improved links to (domestic and foreign) markets of the regional governorates.

\subsection{Summary ${ }^{18}$}

We can summarize the simulation results focusing on the implications of domestic integration for regional growth. We also enable readers to visualize the Egyptian economy so they can explore its spatial nature through interregional backward and forward linkages. We find this helps understanding the different patterns of spatial integration from each region's perspective that are embodied in the results of the exercise.

${ }^{18}$ See Haddad et al. (2011). 


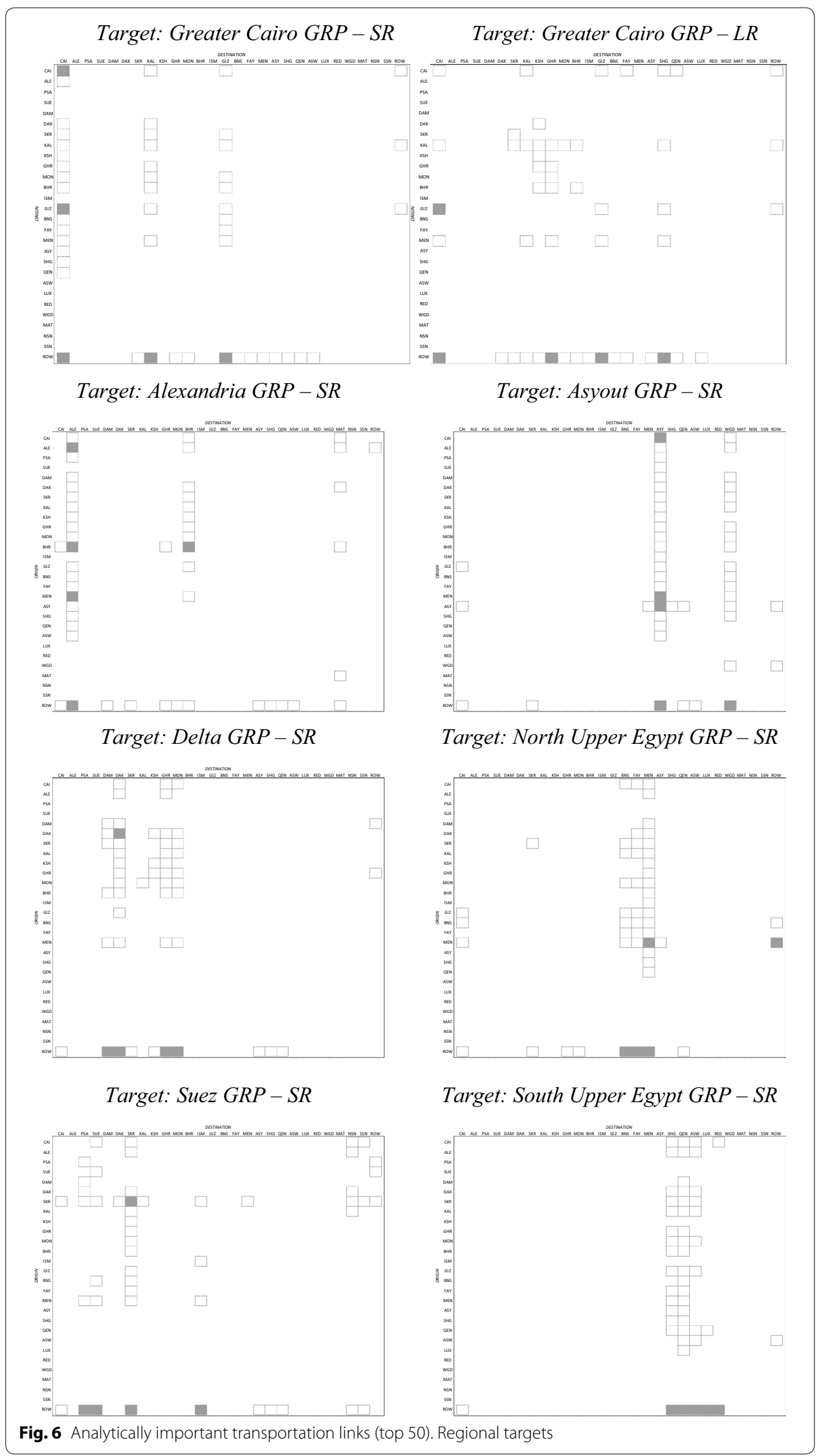




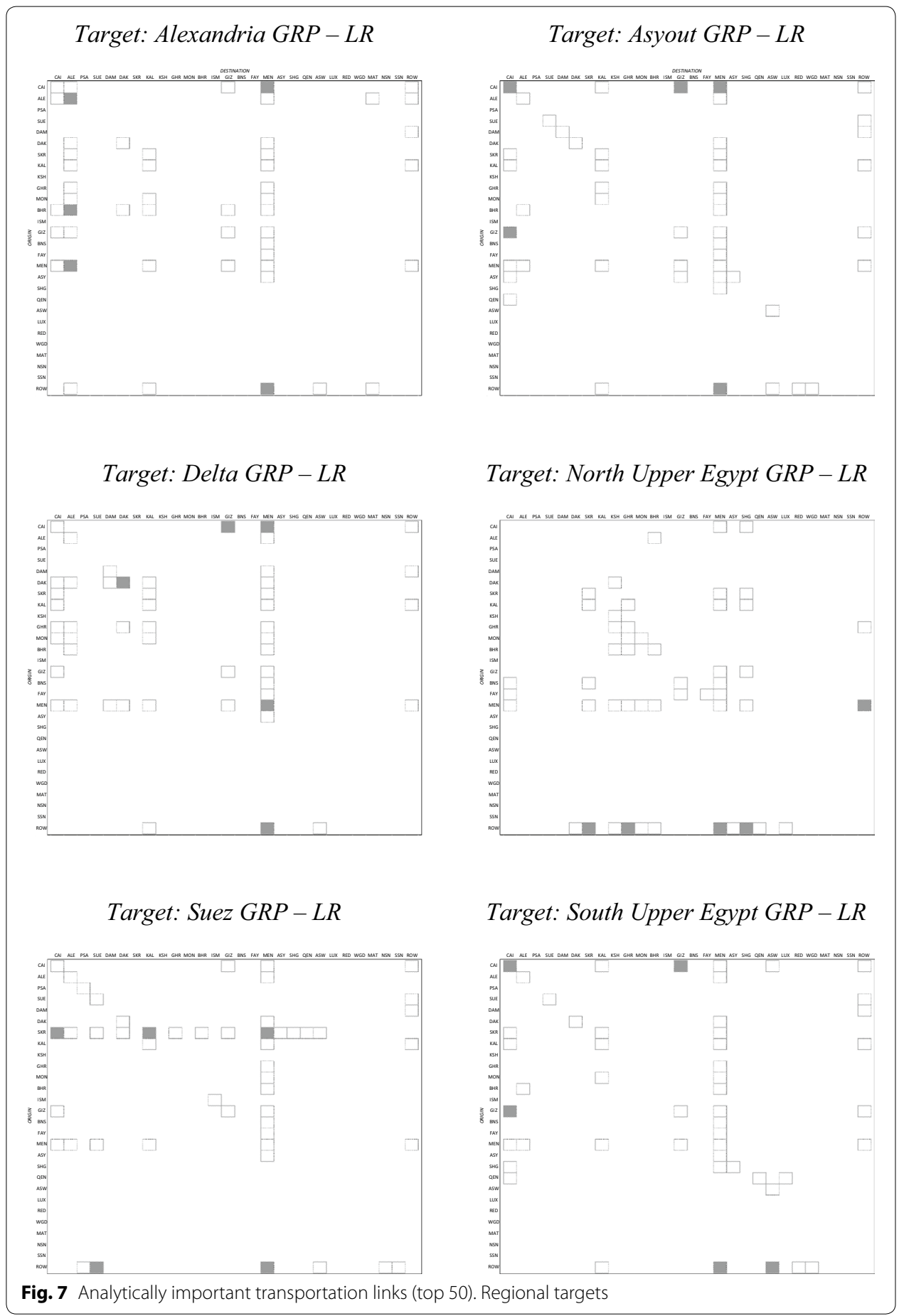

The basic information used to build the $\mathrm{HBC}^{19}$ figures below is drawn from the matrices of results that contain, for each governorate, the GRP effect of reductions in transportation costs for every origin-destination pair in the Egyptian system. A typical 
Table 5 Summary matrix of results for real GRP effects

\begin{tabular}{lll}
\hline Origin & Destination & \\
\cline { 2 - 3 } & $\boldsymbol{r}$ & $\boldsymbol{R}$ \\
\hline$r$ & 0 & $\mathrm{MA}_{r}=\sum_{q} y_{s q}^{r}=y_{s \bullet '}^{r} \quad$ for $s=r$ \\
$R$ & $\mathrm{SA}_{r}=\sum_{s} y_{s q}^{r}=y_{\bullet q^{\prime}}^{r} \quad$ for $q=r$ & $\mathrm{SE}_{r}=\sum_{s} \sum_{q} y_{s q}^{r}=y_{\bullet \bullet}^{r} \quad$ for $s, q \neq r$
\end{tabular}

$R$ study region, $R$ rest of the system (domestic and international)

element of this matrix is $y_{s q}^{r}$, the percentage change in GRP in region $r$, associated with a $1 \%$ reduction in transportation costs from $s$ to $q$.

It is possible to aggregate this information (Table 5) in such a way that we obtain three summary measures reflecting the isolated effects of increasing the region's direct access to markets $\left(\mathrm{MA}_{r}\right)$; increasing direct access to suppliers $\left(\mathrm{SA}_{r}\right)$; as well as the indirect effects associated with transportation costs reductions outside the region-the substitution effects $\left(\mathrm{SE}_{r}\right)$. Notice that we do not consider changes in intraregional trade costs, hence the zero effect in the first cell. ${ }^{20}$

In order to get comparable results for each region, we normalize the information presented in Table 5. Then, we consider the values of $\mathrm{MA}_{r}, \mathrm{SA}_{r}$, and $\mathrm{SE}_{r}$ as vectors and proceed with a normalization based on standard vector analysis. It is important to notice that the sign of the normalized effects remains the same, since we take the norm of each vector.

The normalized vectors for MA and SA are represented in a Cartesian plan, over their respective axes (MA is represented in the $x$-axis and SA is in the $y$-axis), and their vector sum results in a vector that defines the direction and the sense in which the point will be plotted. The following step is to take the intersection of this resultant vector and a circumference with radius one and center in the origin of the Cartesian plan defined before. Departing from this so defined point, we plot the normalized vector of the SE (with the same direction of the resultant vector mentioned above). Positive values for SE are represented as pointing to the center of the circumference, and, thus, fall inside the circle. Negative values, on the other hand, fall outside the circle. This is so that the winning regions, regarding the SE effect, are located inside the circle.

The steps mentioned before produce the areas represented in Fig. 8 with all kinds of signs combinations between the three effects. Taking the data from the Egyptian system, we obtain a comparison of the importance of each effect to the regions, what allows us to better understand the Egyptian interregional system. We end up with the HBC figures for Egypt (Figs. 9, 10).

As can be seen from inspection of Fig. 9, for most governorates we find, in the short run, positive GRP effects related to better access to markets and suppliers, as well as positive effects associated with the substitution effect. ${ }^{21}$ In other words, as overall transportation costs go down, a governorate tends benefit directly from better accessibility to its trade partners, and, indirectly, by trade efficiency improvements related to transportation links outside its direct domain. Furthermore, access to suppliers seems to be

\footnotetext{
${ }^{20}$ For each matrix of results, the main diagonal is zero.

21 Governorates in the area of $\mathrm{MA}(+), \mathrm{SA}(+), \mathrm{SE}(+)$.
} 


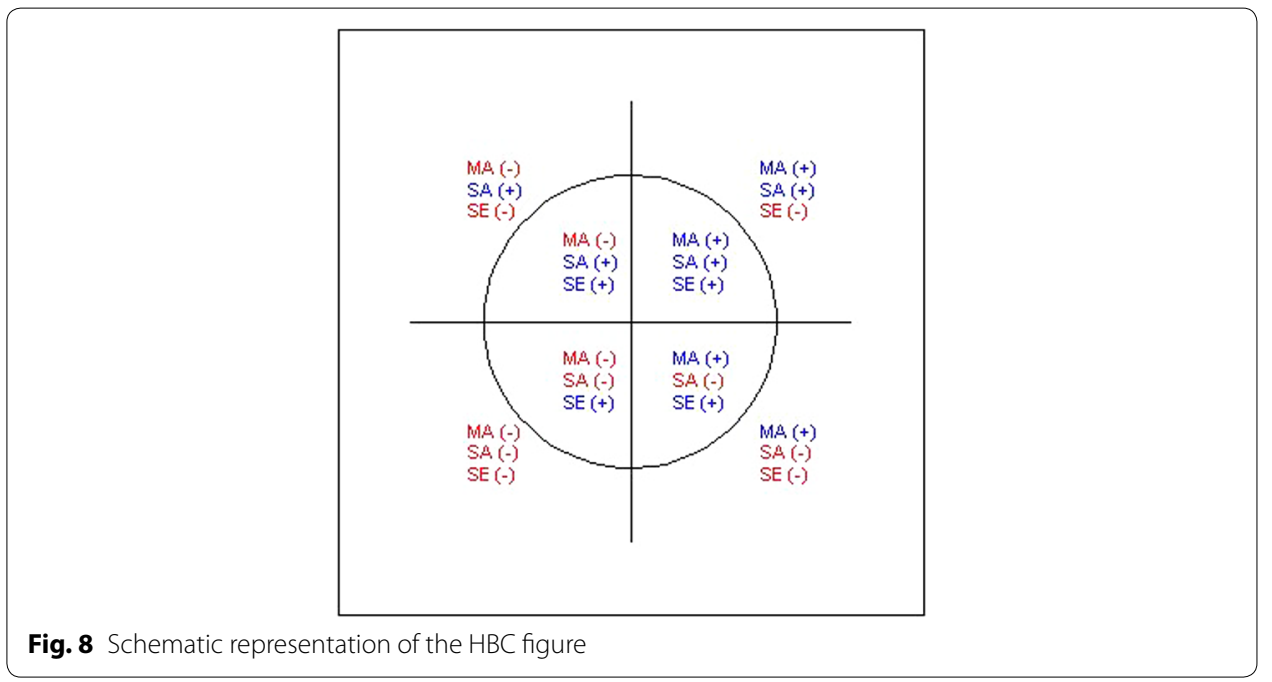

relatively more important than access to markets in the short run. Given our assumption on fixed capital stocks, market access results are weakened by the effects of inelastic supply schedules for capital-intensive sectors. Finally, domestic integration is effectively a tide that lifts all boats-it generates positive overall growth across all Egyptian governorates.

As we allow capital and labor to become mobile, four fairly distinct groups of governorates arise. One common feature is that, for all governorates, better access to markets generates higher GRP in the context of our simulations. For most of them (19 out of 27), improving access to suppliers also affects GRP positively. Still negative effects associated with substitution effects prevail within an important group of governorates. In other words, as overall transportation costs go down, some governorates tend to benefit directly from improved accessibility with trade partners, but are also hampered due to

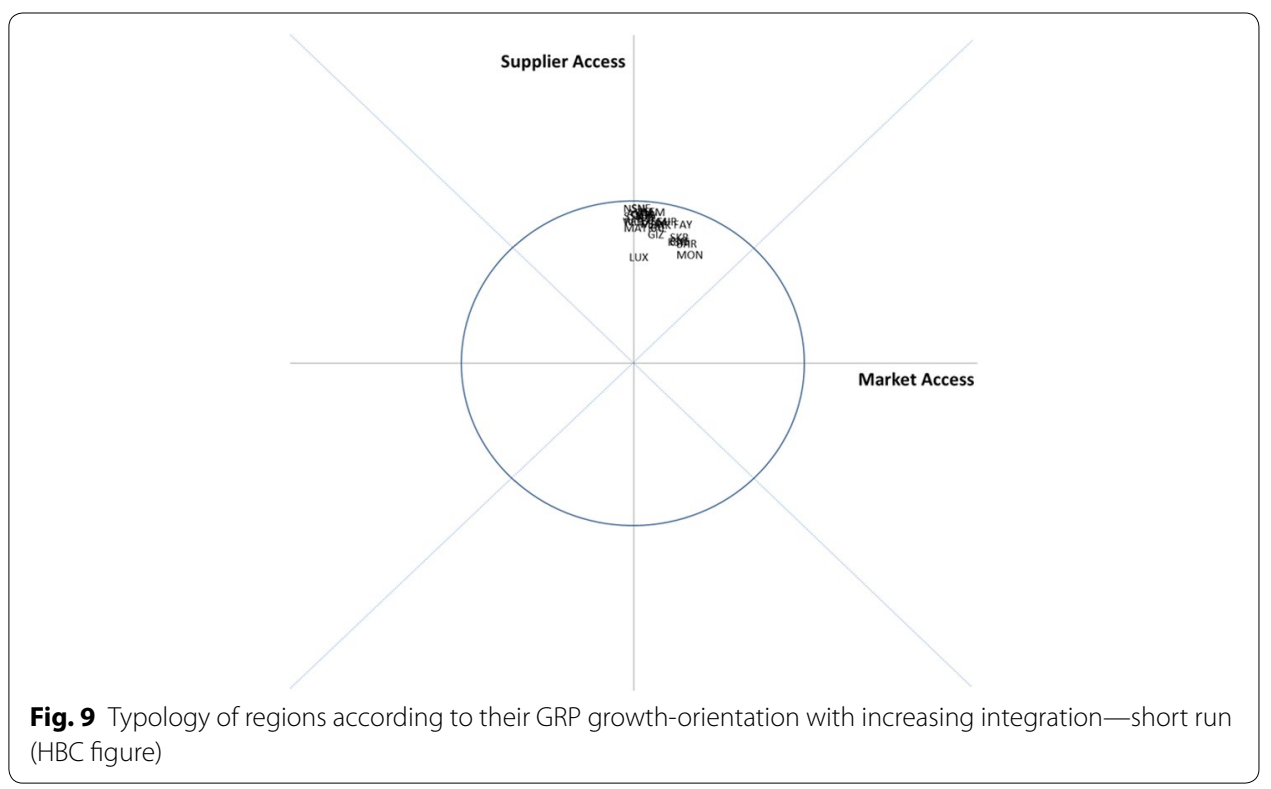




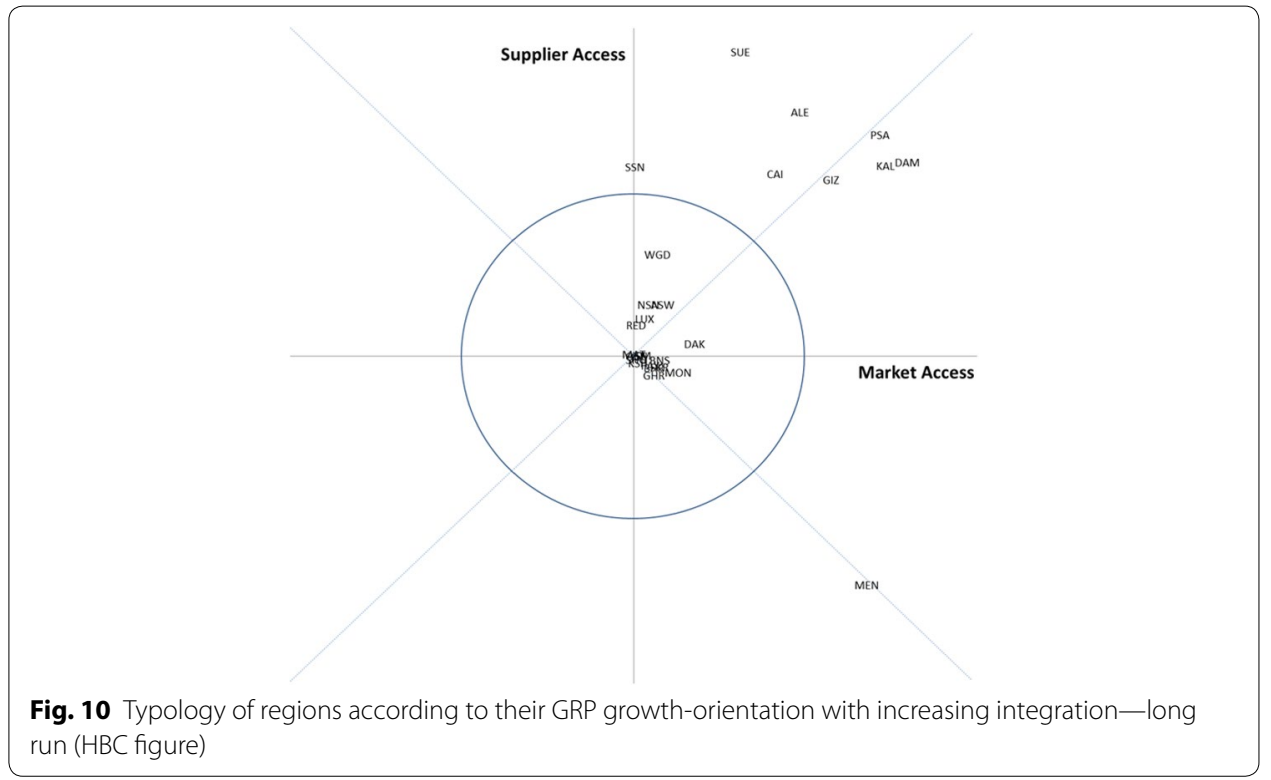

Table 6 Typology of regions according to their GRP growth-orientation with increasing integration-long run

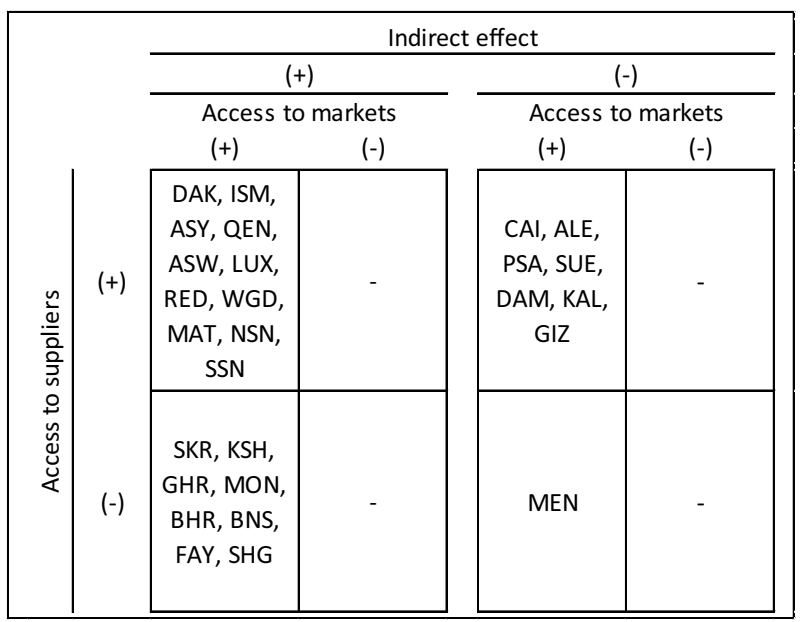

the deviation of traded commodities to more profitable markets (from the perspective of supplying governorates). There is also a subgroup of governorates, whose GRP could potentially be negatively affected by transportation cost reductions to their supplying regions. In such cases, stronger penetration of competing imports hampers local production, reducing GRP. Table 6 shows the governorates classified into the four groups. Note that governorates in the area $\mathrm{MA}(+), \mathrm{SA}(+), \mathrm{SE}(-)$ are either located in the Greater Cairo Region or are homes to main Egyptian ports. This fortifies the idea that the negative substitution effects are likely due to the penetration of competing domestic and foreign imports. 


\section{Network effects}

The analysis in the previous section considered a general perturbation in transportation costs to demonstrate properties of the model. Adding network effects is a natural second step to explore features of our modeling approach in order to reinforce policy relevance for the Egyptian case. What if Egypt foresaw an overall gain in systemic efficiency of its transportation network? Given the structure of the model, which regions would benefit most? Which could be most at risk?

We run a set of simulations in which the speed attributed to each link in the stylized network increases by $10 \%$, increasing travel times and, consequently, transportation costs (Sect. 3). In this context, more remote regions for which transportation costs represent a higher share in their cost structures will face relatively stronger direct impacts. Again, the simulations are carried out under the short- and long-run closure rules. We focus the analysis on the effects on the allocation of economic activity, looking at the model results for changes in GRP. More specifically, we look at the spatial effects and the main structural drivers of the outcomes.

Figure 11 maps the distribution of the GRP impacts across governorates, considering the first two moments of the distributions. The results show that, in general, peripheral, more remote governorates tend to benefit most from large efficiency gains in the network, while governorates in the dynamic core of the country tend to benefit least.

Figure 12 presents the Moran scatterplots ${ }^{22}$ of the two sets of results, as well as the associated spatial correlation coefficients Moran's I. ${ }^{23}$ The calculated values of such coefficients provide an indication that the spatial autocorrelation for GRP impacts is positive in both cases, and stronger in the long run (0.3975 in the short run and 0.4358 in the long run).

How important is the existing economic structure in explaining the short- and longrun spatial results associated with general efficiency gains in the transportation network in Egypt? Do backward and forward linkages matter? How about remoteness? To answer these questions, we regress the simulation results (GRP impacts) against selected structural coefficients of the model. For each set of results, we specify three different models based on different measures of remoteness: cost of shipping exports through Alexandria port (COSTEXP), cost of shipping imports from Alexandria port (COSTIMP), and cost of shipping goods to Cairo (COSTCAI). ${ }^{24}$ The regressions are shown in Tables 7 and 8.

A limited set of structural indicators explain around 90 percent of the variation across governorates in the three specifications for the short-run GRP results (Table 7). Explanations for specific regional results should consider structural and parametric aspects of the data base. Governorates that present higher increases in their output tend to have an overall lower share of foreign imports, benefiting from lower penetration of competing imports; however, the higher the share of interregional imports, the higher the benefit to increase output in the region, as substitution effects at this stage of the chain appear to translate into cost advantages. Also, regions that face stronger positive effects tend to

\footnotetext{
22 The Moran scatterplot shows the spatial lag (i.e. the average of the GRP effects for the neighbors) on the vertical axis and the value at each governorate on the horizontal axis. Note that the variables are expressed in standardized form with mean zero and standard deviation equal to one (Anselin 1999, p. 261).

${ }^{23}$ Formally, this statistics is given by: $/=\frac{n}{\sum \sum w_{i j}} \frac{\sum \sum w_{i j}\left(y_{i}-\bar{y}\right)\left(y_{j}-\bar{y}\right)}{\sum\left(y_{i}-\bar{y}\right)^{2}}$, where $n$ is the number of locations, $y_{i}$ is the data value of attribute in analysis (in our case, GRP impacts), $w_{i j}$ is a spatial weight for the pair of locations $i$ and $j$.

${ }^{24}$ Correlation between any two of these variables is very high: COSTEXP - COSTIMP $=0.9969 ;$ COSTEXP - COST$C A I=0.8767 ;$ COSTIMP - COSTCAI $=0.8710$.
} 

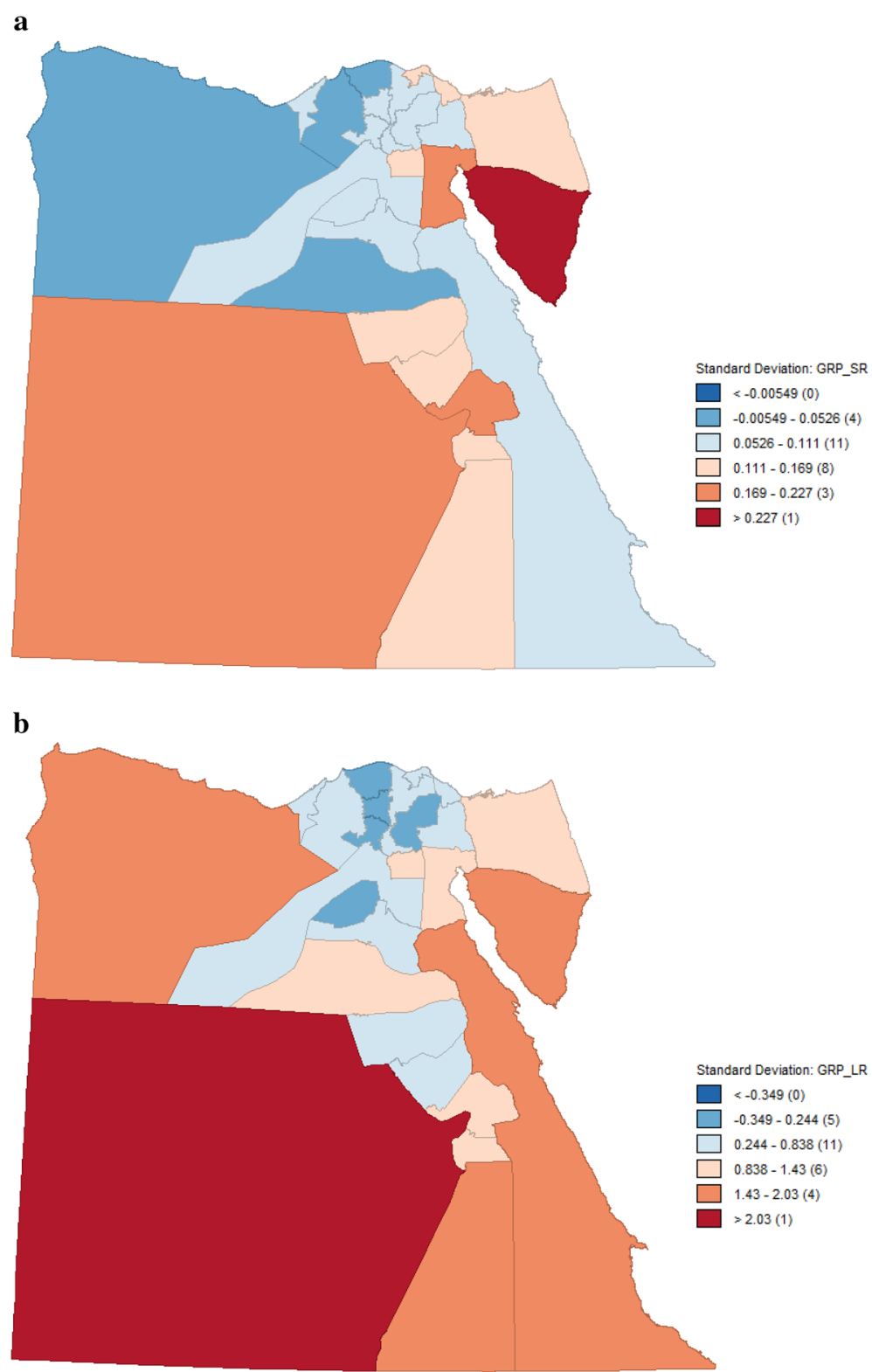

Fig. 11 Effects of $10 \%$ increase in the network speed on GRP_standard deviation maps. a Short run and b long run

present a larger share of their sales to foreign consumers. A higher capital/labor ratio seems to hamper economic performance in the short run, as employment expansion turns out to be less feasible. Finally, governorates with initial higher transportation costs to foreign (COSTEXP) and domestic (COSTCAI) markets, as well as those with higher initial costs of shipping foreign imports to their local markets (COSTIMP) appear more likely to be affected positively by policies enabling the transportation improvements.

In the long run, the peripheral governorates also obtain GRP benefits from the shock. The impact of the efficiency gains in the network favors activity levels outside Egypt's core. In fact the periphery gains at the expense of the core, particularly the delta regions. 

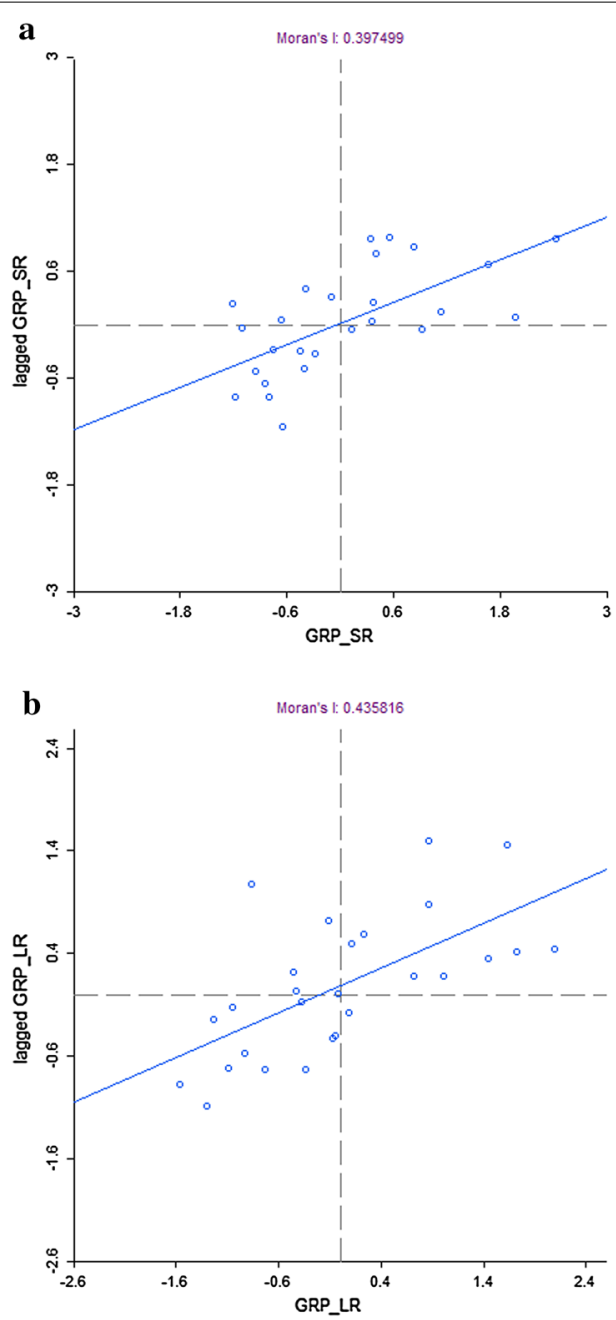

Fig. 12 Effects of $10 \%$ increase in the network speed on GRP—Moran scatterplot. a Short run, b long run

Thus, a relative spatial deconcentration of national GDP arises. Structural indicators related to import penetration $(-)$, foreign export shares $(+)$, and the three measures of remoteness $(+)$ play a similar role in the long run. However, forward linkages in domestic markets - as measured by the share of interregional exports in total sales-are most relevant to understanding GRP effects in the long run. Together, the selected structural indicators explain over 80 percent of the variation in GRP across governorates (Table 8).

\section{Final remarks}

There is a growing need for economic and socio-economic models for helping improving road management (World Road Association 2003, p. 7). This paper provides an attempt to meet this requirement in a developing country. We use a fully operational ICGE model implemented for the Egyptian economy. As noted elsewhere (Haddad et al. 2011a, b, p. 46), the existing, commonly used policy tools to address issues related to the economic impacts of transportation infrastructure policies do not depict well critical channels through which exogenous and transportation policy shocks are transmitted to 
Table 7 Structural analysis of short-run GRP results

\begin{tabular}{|c|c|c|c|c|}
\hline Variable & Coefficient & SE & $t$-Statistic & Prob. \\
\hline \multicolumn{5}{|c|}{ Dependent variable: GRP_SR } \\
\hline FOR & -0.03547 & 0.00741 & -4.78 & 0.000 \\
\hline EXP & 0.00190 & 0.00050 & 3.81 & 0.001 \\
\hline INTER & 0.00341 & 0.00115 & 2.96 & 0.007 \\
\hline COSTIMP & 0.00002 & $4.55 e-06$ & 4.43 & 0.000 \\
\hline$K L$ & -0.01381 & 0.00325 & -4.25 & 0.000 \\
\hline Constant & 0.50978 & 0.12741 & 4.00 & 0.001 \\
\hline$R^{2}$ & 0.8964 & & & \\
\hline \multicolumn{5}{|c|}{ Dependent variable: GRP_SR } \\
\hline FOR & -0.03540 & 0.0071 & -4.98 & 0.000 \\
\hline EXP & 0.00182 & 0.00048 & 3.79 & 0.001 \\
\hline INTER & 0.00330 & 0.00112 & 2.95 & 0.008 \\
\hline COSTEXP & 0.00002 & $4.34 \mathrm{e}-06$ & 4.72 & 0.000 \\
\hline$K L$ & -0.01389 & 0.00315 & -4.41 & 0.000 \\
\hline Constant & 0.51351 & 0.12160 & 4.22 & 0.000 \\
\hline$R^{2}$ & 0.9028 & & & \\
\hline \multicolumn{5}{|c|}{ Dependent variable: GRP_SR } \\
\hline FOR & -0.03890 & 0.00796 & -4.89 & 0.000 \\
\hline EXP & 0.00191 & 0.00055 & 3.49 & 0.002 \\
\hline INTER & 0.00371 & 0.00126 & 2.94 & 0.008 \\
\hline COSCAl & 0.00067 & 0.00019 & 43.56 & 0.002 \\
\hline$K L$ & -0.0141 & 0.00358 & -3.94 & 0.001 \\
\hline Constant & 0.55779 & 0.13847 & 4.03 & 0.001 \\
\hline$R^{2}$ & 0.8750 & & & \\
\hline
\end{tabular}

Obs.: GRP_SR percentage change in GRP, FOR import penetration in total consumption, EXP export share in total sales, INTER interregional share in total consumption, COSTEXP cost of shipping exports through Alexandria port, COSTIMP cost of shipping imports from Alexandria port, COSTCAl cost of shipping goods to Cairo, $K L$ capital-labor ratio

the various dimensions of regional economic structures. This paper looks at the Egyptian case. It yields quantitative and qualitative insights (general equilibrium effects) into trade-offs commonly faced by policy makers when dealing with infrastructure projects in a spatial context. It shows that, given different policy options, decision makers face nontrivial choices, as different projects perform differently in different dimensions, usually presenting outcomes with different hierarchies related to multidimensional policy goals.

However, the reported simulations relate to prospective studies of general relevance for the understanding of the Egyptian integrated regional systems under the analytical, functional and numerical structures embedded in the model. Little emphasis is given to specific problems of the national reality. In other words, at this stage, the use of Egyptian data to calibrate the ICGE model has the main role to demonstrate the ability of the modeling system to be applied for the country. Although relevant for the Egyptian case, the simulations represent generic scenarios of domestic integration, providing, at most, a heuristic validation about the proper functioning of the model rather than useful results to support policy decisions.

In this sense, the modeling effort reported here is just a start, and this paper is a mere demonstration of the framework's potential. We find the model is clearly ready to address concrete economic issues that address planning needs. Such methods of interregional 
Table 8 Structural analysis of long-run GRP results

\begin{tabular}{|c|c|c|c|c|}
\hline Variable & Coefficient & SE & $t$-Statistic & Prob. \\
\hline \multicolumn{5}{|c|}{ Dependent variable: GRP_LR } \\
\hline FOR & -0.39416 & 0.09334 & -4.22 & 0.000 \\
\hline EXP & 0.01897 & 0.00594 & 3.19 & 0.004 \\
\hline SINTER & 0.01716 & 0.00585 & 2.94 & 0.008 \\
\hline COSTIMP & 0.00026 & 0.00006 & 4.49 & 0.000 \\
\hline Constant & 5.31718 & 1.52570 & 3.49 & 0.002 \\
\hline$R^{2}$ & 0.8317 & & & \\
\hline \multicolumn{5}{|c|}{ Dependent variable: GRP_LR } \\
\hline FOR & -0.39860 & 0.09180 & -4.34 & 0.000 \\
\hline EXP & 0.01770 & 0.00590 & 3.00 & 0.007 \\
\hline SINTER & 0.01719 & 0.00580 & 2.96 & 0.007 \\
\hline COSTEXP & 0.00026 & 0.00006 & 4.57 & 0.000 \\
\hline Constant & 5.40834 & 1.49628 & 3.61 & 0.002 \\
\hline$R^{2}$ & 0.8342 & & & \\
\hline \multicolumn{5}{|c|}{ Dependent variable: GRP_LR } \\
\hline FOR & -0.42954 & 0.09558 & -4.49 & 0.000 \\
\hline EXP & 0.02066 & 0.00628 & 3.29 & 0.003 \\
\hline SINTER & 0.01596 & 0.00617 & 2.59 & 0.017 \\
\hline COSTCAI & 0.00909 & 0.00228 & 3.99 & 0.001 \\
\hline Constant & 5.94323 & 1.55394 & 3.82 & 0.001 \\
\hline$R^{2}$ & 0.8129 & & & \\
\hline
\end{tabular}

Obs.: GRP_LR percentage change in GRP, FOR import penetration in total consumption, EXP export share in total sales, SINTER interregional share in total sales, COSTEXP cost of shipping exports through Alexandria port, COSTIMP cost of shipping imports from Alexandria port, COSTCAl cost of shipping goods to Cairo

analysis are ultimately developed to evaluate the relative potential of policies. While it is important to know that transportation costs will decline in the face of related infrastructure investments, it is generally more important to be able to know how those cost reductions will affect the broader economic and social systems-at least in terms of the general magnitude and direction (positively or negatively). When planning, being able to drill down for more detail (spatially and sectorally) can be quite important. In this vein, having the proper set of policy tools can enable consistent and comparable quantitative assessments of alternative strategies across sets of compatible or even competing policy alternatives.

In the aforementioned World Bank (2012) report Reshaping Egypt's Economic Geography: Domestic Integration as a Development Platform, the chapter by Felkner et al. (2012) addresses some of these issues, in the Egyptian case. It does so by simulating, via GIS, the impacts on accessibility (policy target) under three alternative infrastructure improvement scenarios. ${ }^{25}$ Their results indicate that improvements in more congested areas tended to have superior network-wide cost savings across Egypt when compared to those improvements connecting to "lagging" areas. We obtain similar results for incremental infrastructure projects in a short-run framework. But we also find that

\footnotetext{
25 The scenarios were specifically identified in discussions with Egyptian infrastructure experts as being key to the overall development of the larger Egyptian transport infrastructure: playing a key role in connecting key regions of Egypt providing improved transport corridors to facilitate increased trade and shipping of goods, or facilitating transport for major metropolitan populations.
} 
transportation infrastructure mega-projects could induce the spatial deconcentration of economic activity in the long run. Thus, it is clear that the choice of a "best" transportation infrastructure program depends on policy intentions. Trade-offs vary with the nature of transportation investment alternatives: timing of outcomes (short run vs. long run), spatial distribution of socio-economic effects (regional vs. national), and who benefits are just some of the trade-offs policymakers face.

Models are issue-specific; developing policy priorities based on answers from models that are inadequate for articulating particular issues can cause severe unintentional consequences to crop up in the course of policymaking (see Agénor et al. 2007). It is therefore important for policy analysts to maintain a reasonably broad array of instruments in their tool bag. Our paper illustrates the potential of a unified interregional economic modeling approach for Egypt. Further amendments to it will cope with methodological advances in both economic and transport modeling. ${ }^{26}$ Still, we believe it already enables a fuller appreciation of a broader set of dimensions to Egyptian transportation policy.

Competing interests

The authors declare that they have no competing interests.

Author details

${ }^{1}$ Department of Economics, University of Sao Paulo, Av. Prof. Luciano Gualberto, 908, FEA I, Cidade Universitária, São Paulo, SP 05508-900, Brazil. ${ }^{2}$ NEREUS - The University of Sao Paulo Regional and Urban Economics Lab, São Paulo, Brazil. ${ }^{3}$ EJB School of Planning and Public Policy, Rutgers University, New Brunswick, NJ, USA. ${ }^{4}$ Department of Economics, Faculty of Commerce, Zagazig University, Zagazig, Egypt.

\section{Appendix: The equation system of the ICGE model}

The functional forms of the main groups of equations of the ICGE core are presented in this Appendix together with the definition of the main groups of variables, parameters and coefficients.

The notational convention uses uppercase letters to represent the levels of the variables and lowercase for their percentage-change representation. Superscripts $(u), u=0,1 j, 2 j, 3$, 4,5 , refer, respectively, to output (0) and to the five different regional-specific users of the products identified in the model: producers in sector $j(1 j)$, investors in sector $j(2 j)$, households (3), purchasers of exports (4), and government (5); the second superscript identifies the domestic region where the user is located. Inputs are identified by two subscripts: the first takes the values $1, \ldots, g$, for commodities, $g+1$, for primary factors, and $g+2$, for "other costs" (basically, taxes and subsidies on production); the second subscript identifies the source of the input, being it from domestic region $b(1 b)$ or imported (2), or coming from labor (1) or capital (2). The symbol (•) is employed to indicate a sum over an index.

\section{Equations}

Substitution between products from different regional domestic sources.

$$
\begin{aligned}
& x_{(i(1 b))}^{(u) r}=x_{(i(1 \bullet))}^{(u) r}-\sigma_{(i)}^{(u) r}\left(p_{(i(1 b))}^{(u) r}-\sum_{l \in S^{*}}\left(V(i, 1 l,(u), r) / V(i, 1 \bullet,(u), r)\left(p_{(i(1 l))}^{(u) r}\right)\right)\right) \\
& i=1, \ldots, g ; b=1, \ldots, q ;(u)=3 \text { and }(k j) \text { for } k=1 \text { and } 2 \text { and } \quad j=1, \ldots, h ; r=1, \ldots, R
\end{aligned}
$$

26 The integration of the modeling in Felkner et al. (2012) within our modeling framework developed is a promising way forward. 
Substitution between domestic and imported products

$x_{(i s)}^{(u) r}=x_{(i \bullet)}^{(u) r}-\sigma_{(i)}^{(u) r}\left(p_{(i s)}^{(u) r}-\sum_{l=1 \bullet, 2}\left(V(i, l,(u), r) / V(i, \bullet,(u), r)\left(p_{(i l)}^{(u) r}\right)\right)\right)$

$i=1, \ldots, g ; s=1 \bullet$ and $2 ;(u)=3$ and $(k j)$ for $k=1 e 2$ and $j=1, \ldots, h ; r=1, \ldots, R$

Substitution between labor and capital

$$
\begin{aligned}
& x_{(g+1, s)}^{(1 j) r}-a_{(g+1, s)}^{(1 j) r}=\alpha_{(g+1, s)}^{(1 j) r} x_{(g+1 \bullet)}^{(1 j) r}-\sigma_{(g+1)}^{(1 j) r} \\
& \quad\left\{p_{(g+1, s)}^{(1 j) r}+a_{(g+1, s)}^{(1 j) r}-\sum_{l=1,2}(V(g+1, l,(1 j), r) / V(g+1, \bullet,(1 j), r))\left(p_{(g+1, l)}^{(1 j) r}+a_{(g+1, l)}^{(1 j) r}\right)\right\} \\
& \quad j=1, \ldots, h ; s=1 \text { and } 2 ; r=1, \ldots, R
\end{aligned}
$$

Intermediate and investment demands for composites commodities and primary factors

$$
\begin{array}{rl}
x_{(i \bullet)}^{(u) r}=z^{(u) r}+a_{(i)}^{(u) r} & u=(k j) \text { for } k=1,2 \text { and } j=1, \ldots, h \\
& \text { if } u=(1 j) \text { then } i=1, \ldots, g+2 \\
& \text { if } u=(2 j) \text { then } i=1, \ldots, g \\
& r=1, \ldots, R
\end{array}
$$

Household demands for composite commodities

$$
\begin{aligned}
& V(i, \bullet,(3), r)\left(p_{(i \bullet)}^{(3) r}+x_{(i \bullet}^{(3) r}\right)=\gamma_{(i)}^{r} P_{(i \bullet)}^{(3) r} Q^{r}\left(p_{(i \bullet)}^{(3) r}+x_{(i \bullet)}^{(3) r}\right)+\beta_{(i)}^{r}\left(C^{r}-\sum_{j \in G} \gamma_{(j)}^{r} P_{(i \bullet}^{(3) r} Q^{r}\left(p_{(i \bullet)}^{(3) r}+x_{(i \bullet)}^{(3) r}\right)\right)_{(5)} \\
& i=1, \ldots, g ; r=1, \ldots, R
\end{aligned}
$$

Purchasers' prices related to basic prices and margins (trade costs)

$$
\begin{aligned}
V(i, s,(u), r) p_{(i s)}^{(u) r} & =(B(i, s,(u), r))+\sum_{m \in G} M(m, i, s,(u), r) p_{(m 1)}^{(0) r}, \\
& i=1, \ldots, g ;(u)=(3),(4),(5) \\
& \text { and }(k j) \text { for } k=1,2 \text { and } j=1, \ldots, h ; s=1 b, 2 \text { for } b=1, \ldots, q \\
& r=1, \ldots, R
\end{aligned}
$$

Foreign demands (exports) for domestic goods

$$
\left(x_{(i s)}^{(4) r}-f q_{(i s)}^{(4) r}\right)=\eta_{(i s)}^{r}\left(p_{(i s)}^{(4) r}-e-f p_{(i s)}^{(4) r}\right), \quad i=1, \ldots, g ; s=1 b, 2 \text { for } b=1, \ldots, q ; r=1, \ldots, R
$$

Government demands

$$
x_{(i s)}^{(5) r}=x_{(\bullet \bullet)}^{(3) r}+f_{(i s)}^{(5) r}+f^{(5) r}+f^{(5)} \quad i=1, \ldots, g ; s=1 b, 2 \text { for } b=1, \ldots, q ; r=1, \ldots, R
$$

Margins demands for domestic goods

$$
\begin{array}{rl}
x_{(m 1)}^{(i s)(u) r}=x_{(i s)}^{(u) r}+a_{(m 1)}^{(i s)(u) r} & m, i=1, \ldots, g ; \\
& (u)=(3),(4 b) \text { for } b=1, \ldots, r,(5) \text { and }(k j) \text { for } k=1,2 ;(9) \\
& j=1, \ldots, h ; s=1 b, 2 \text { for } b=1, \ldots, r ; \\
& r=1, \ldots, R
\end{array}
$$


Demand equals supply for regional domestic commodities

$$
\begin{aligned}
& \sum_{j \in H} Y(l, j, r) x_{(l 1)}^{(0 j) r}=\sum_{u \in U} B(l, 1,(u), r) x_{(l 1)}^{(u) r}+\sum_{i \in G} \sum_{s \in S} \sum_{u \in U} M(l, i, s,(u), r) x_{(l 1)}^{(i s)(u) r} \\
& \quad l=1, \ldots, g ; r=1, \ldots, R
\end{aligned}
$$

Regional industry revenue equals industry costs

$$
\sum_{l \in G} Y(l, j, r)\left(p_{(l 1)}^{(0) r}+a_{(l 1)}^{(0) r}\right)=\sum_{l \in G *} \sum_{s \in S} V(l, s,(1 j), r)\left(p_{(l s)}^{(1 j) r}\right), \quad j=1, \ldots, h ; r=1, \ldots, R
$$

Basic price of imported commodities

$$
p_{(i(2))}^{(0)}=p_{(i(2))}^{(w)}-e+t_{(i(2))}^{(0)}, \quad i=1, \ldots, g
$$

Cost of constructing units of capital for regional industries

$$
\begin{gathered}
V(\bullet, \bullet,(2 j), r)\left(p_{(k)}^{(1 j) r}-a_{(k)}^{(1 j) r}\right)=\sum_{i \in G} \sum_{s \in S} V(i, s,(2 j), r)\left(p_{(i s)}^{(2 j) r}+a_{(i s)}^{(2 j) r}\right), \\
j=1, \ldots, h ; r=1, \ldots, R
\end{gathered}
$$

Investment in period $T$

$X_{(g+1,2)}^{(1 j) r}(1) x_{(g+1,2)}^{(1 j) r}(1)=X_{(g+1,2)}^{(1 j) r}\left(1-\delta_{j}\right) x_{(g+1,2)}^{(1 j) r}+Z^{(2 j) r} z^{(2 j) r} \quad j=1, \ldots, h ; r=1, \ldots, R$

Capital stock in period $T+1$-comparative statics

$$
x_{(g+1,2)}^{(1 j) r}(1)=x_{(g+1,2)}^{(1 j) r} \quad j=1, \ldots, h ; r=1, \ldots, R
$$

Definition of rates of return to capital

$$
r_{(j)}^{r}=Q_{(j)}^{r}\left(p_{(g+1,2)}^{(1 j) r}-p_{(k)}^{(1 j) r}\right), \quad j=1, \ldots, h ; r=1, \ldots, R
$$

Relation between capital growth and rates of return

$$
r_{(j)}^{r}-\omega=\varepsilon_{(j)}^{r}\left(x_{(g+1,2)}^{(1 j) r}-x_{(g+1,2)}^{(\bullet) r}\right)+f_{(k)}^{(2 j) r}, \quad j=1, \ldots, h ; r=1, \ldots, R
$$

Other definitions in the CGE core include: import volume of commodities, components of regional/national GDP, regional/national price indices, wage settings, definitions of factor prices, employment aggregates, and accounting identities.

\section{Variables}




\begin{tabular}{|c|c|c|}
\hline Variable & Index ranges & Description \\
\hline$x_{(i s)}^{(u) r}$ & $\begin{array}{l}(u)=(3)(4),(5),(6) \text { and } \\
(k j) \text { for } k=1,2 \text { and } j=1, \ldots, h ; \\
\text { if }(u)=(1 j) \text { then } i=1, \ldots, g+2 ; \\
\text { if }(u) \neq(1 j) \text { then } i=1, \ldots, g ; \\
s=1 b, 2 \text { for } b=1, \ldots, q ; \text { and } i=1, \ldots, g \text { and } \\
s=1,2,3 \text { for } i=g+1 \\
r=1, \ldots, R\end{array}$ & $\begin{array}{l}\text { Demand by user }(u) \text { in region } r \text { for good or primary } \\
\text { factor (is) }\end{array}$ \\
\hline$p_{(i s)}^{(u) r}$ & $\begin{array}{l}(u)=(3),(4),(5),(6) \text { and } \\
(k j) \text { for } k=1,2 \text { and } j=1, \ldots, h ; \\
\text { if }(u)=(1 j) \text { then } i=1, \ldots, g+2 ; \\
\text { if }(u) \neq(1 j) \text { then } i=1, \ldots, g ; \\
s=1 b, 2 \text { for } b=1, \ldots, q ; \text { and } i=1, \ldots, g \text { and } \\
s=1,2,3 \text { for } i=g+1 \\
r=1, \ldots, R\end{array}$ & $\begin{array}{l}\text { Price paid by user }(u) \text { in region } r \text { for good or primary } \\
\text { factor (is) }\end{array}$ \\
\hline$x_{(i \bullet)}^{(u) r}$ & $\begin{array}{l}(u)=(3) \text { and }(k j) \text { for } k=1,2 \text { and } \\
j=1, \ldots, h \text {. } \\
\text { if }(u)=(1 j) \text { then } i=1, \ldots, g+1 \text {; } \\
\text { if }(u) \neq(1 j) \text { then } i=1, \ldots, g \\
r=1, \ldots, R\end{array}$ & $\begin{array}{l}\text { Demand for composite good or primary factor } i \text { by } \\
\text { user }(u) \text { in region } r\end{array}$ \\
\hline$a_{(g+1, s)}^{(1 j) r}$ & $\begin{array}{l}j=1, \ldots, h \text { and } s=1,2,3 \\
r=1, \ldots, R\end{array}$ & $\begin{array}{l}\text { Primary factor saving technological change in } \\
\text { region } r\end{array}$ \\
\hline$a_{(i)}^{(u) r}$ & $\begin{array}{l}i=1, \ldots, g,(u)=(3) \text { and }(k j) \text { for } k=1,2 \text { and } \\
j=1, \ldots, h \\
r=1, \ldots, R\end{array}$ & $\begin{array}{l}\text { Technical change related to the use of good } i \text { by } \\
\text { user }(u) \text { in region } r\end{array}$ \\
\hline$C^{r}$ & & Total expenditure by regional household in region $r$ \\
\hline$Q^{r}$ & & Number of households \\
\hline$z^{(u) r}$ & $\begin{array}{l}(u)=(k j) \text { for } k=1,2 \text { and } j=1, \ldots, h \\
r=1, \ldots, R\end{array}$ & $\begin{array}{l}\text { Activity levels: current production and investment } \\
\text { by industry in region } r\end{array}$ \\
\hline$f q_{(i s)}^{(4) r}$ & $\begin{array}{l}i=1, \ldots, g ; s=1 b, 2 \text { for } b=1, \ldots, q \\
r=1, \ldots, R\end{array}$ & $\begin{array}{l}\text { Shift (quantity) in foreign demand curves for } \\
\text { regional exports }\end{array}$ \\
\hline$f p_{(i s)}^{(4) r}$ & $\begin{array}{l}i=1, \ldots, g ; s=1 b, 2 \text { for } b=1, \ldots, q \\
r=1, \ldots, R\end{array}$ & $\begin{array}{l}\text { Shift (price) in foreign demand curves for regional } \\
\text { exports }\end{array}$ \\
\hline$e$ & & Exchange rate \\
\hline$x_{(m 1)}^{(i s)(u) r}$ & $\begin{array}{l}m, i=1, \ldots, g ; s=1 b, 2 \text { for } b=1, \ldots, q \\
(u)=(3),(4),(5) \text { and } \\
(k j) \text { for } k=1,2 \text { and } j=1, \ldots, h \\
r=1, \ldots, R\end{array}$ & $\begin{array}{l}\text { Demand for commodity }(m 1) \text { to be used as a mar- } \\
\text { gin to facilitate the flow of }(i s) \text { to }(u) \text { in region } r\end{array}$ \\
\hline$a_{(m 1)}^{(i s)(u) r}$ & $\begin{array}{l}m, i=1, \ldots, g ; s=1 b, 2 \text { for } b=1, \ldots, q \\
(u)=(3),(4),(5) \text { and } \\
(k j) \text { for } k=1,2 \text { and } j=1, \ldots, h \\
r=1, \ldots, R\end{array}$ & $\begin{array}{l}\text { Technical change related to the demand for com- } \\
\text { modity }(m 1) \text { to be used as a margin to facilitate } \\
\text { the flow of (is) to }(u) \text { in region } r\end{array}$ \\
\hline$x_{(i 1)}^{(0 j) r}$ & $\begin{array}{l}i=1, \ldots, g ; j=1, \ldots, h \\
r=1, \ldots, R\end{array}$ & Output of domestic good $i$ by industry $j$ \\
\hline$p_{(i s)}^{(0) r}$ & $\begin{array}{l}i=1, \ldots, g ; s=1 b, 2 \text { for } b=1, \ldots, q \\
r=1, \ldots, R\end{array}$ & Basic price of good $i$ in region $r$ from source $s$ \\
\hline$p_{(i(2))}^{(w)}$ & $i=1, \ldots, g$ & USD c.iff. price of imported commodity $i$ \\
\hline$f_{(k)}^{(2 j) r}$ & $\begin{array}{l}j=1, \ldots, h \\
r=1, \ldots, R\end{array}$ & Regional-industry-specific capital shift terms \\
\hline$x_{(g+1,2)}^{(1 j) r}(1)$ & $\begin{array}{l}j=1, \ldots, h \\
r=1, \ldots, R\end{array}$ & $\begin{array}{l}\text { Capital stock in industry } j \text { in region } r \text { at the end of } \\
\text { the year, i.e., capital stock available for use in the } \\
\text { next year }\end{array}$ \\
\hline$p_{(k)}^{(1 j) r}$ & $\begin{array}{l}j=1, \ldots, h \\
r=1, \ldots, R\end{array}$ & $\begin{array}{l}\text { Cost of constructing a unit of capital for industry } j \\
\text { in region } r\end{array}$ \\
\hline$f_{(i s)}^{(5) r}$ & $\begin{array}{l}i=1, \ldots, g ; s=1 b, 2 \text { for } b=1, \ldots, q \\
r=1, \ldots, R\end{array}$ & $\begin{array}{l}\text { Commodity and source-specific shift term for } \\
\text { government expenditures in region } r\end{array}$ \\
\hline$f^{(5) r}$ & $r=1, \ldots, R$ & Shift term for government expenditures in region $r$ \\
\hline$f^{(5)}$ & & Shift term for government expenditures \\
\hline$\omega$ & & Overall rate of return on capital (short run) \\
\hline
\end{tabular}




\begin{tabular}{lll}
\hline Variable & Index ranges & Description \\
\hline$r_{(j)}^{r}$ & $j=1, \ldots, h$ & Regional-industry-specific rate of return \\
& $r=1, \ldots, R$ & \\
\hline
\end{tabular}

Parameters, coefficients and sets

\begin{tabular}{|c|c|}
\hline Symbol & Description \\
\hline$\sigma_{(i)}^{(u) r}$ & $\begin{array}{l}\text { Parameter: elasticity of substitution between alternative sources of commodity or factor } \\
\text { i for user }(u) \text { in region } r\end{array}$ \\
\hline$\sigma^{(0 j) r}$ & $\begin{array}{l}\text { Parameter: elasticity of transformation between outputs of different commodities in } \\
\text { industry } j \text { in region } r\end{array}$ \\
\hline$\alpha_{(g+1, s)}^{(1 j) r}$ & Parameter: returns to scale to individual primary factors in industry $j$ in region $r$ \\
\hline$\beta_{(i)}^{r}$ & $\begin{array}{l}\text { Parameter: marginal budget shares in linear expenditure system for commodity } i \text { in } \\
\text { region } r\end{array}$ \\
\hline$\gamma_{(i)}^{r}$ & $\begin{array}{l}\text { Parameter: subsistence parameter in linear expenditure system for commodity } i \text { in } \\
\text { region } r\end{array}$ \\
\hline$\varepsilon_{(j)}^{r}$ & Parameter: sensitivity of capital growth to rates of return of industry $j$ in region $r$ \\
\hline$\eta_{(i s)}^{r}$ & Parameter: foreign elasticity of demand for commodity $i$ from region $r$ \\
\hline$B(i, s,(u), r)$ & Input-output flow: basic value of (is) used by $(u)$ in region $r$ \\
\hline$M(m, i, s,(u), r)$ & $\begin{array}{l}\text { Input-output flow: basic value of domestic good } m(m=\text { trade) used as a margin to } \\
\text { facilitate the flow of }(i s) \text { to }(u) \text { in region } r\end{array}$ \\
\hline$V(i, s,(u), r)$ & $\begin{array}{l}\text { Input-output flow: purchasers'value of good or factor } i \text { from source s used by user }(u) \text { in } \\
\text { region } r\end{array}$ \\
\hline$Y(i, j, r)$ & Input-output flow: basic value of output of domestic good $i$ by industry $j$ from region $r$ \\
\hline$Q_{(j)}^{r}$ & Coefficient: ratio, gross to net rate of return \\
\hline G & Set: $\{1,2, \ldots, g\}, g$ is the number of composite goods \\
\hline$G^{*}$ & Set: $\{1,2, \ldots, g+1\}, g+1$ is the number of composite goods and primary factors \\
\hline$H$ & Set: $\{1,2, \ldots, h\}, h$ is the number of industries \\
\hline$U$ & Set: $\{(3),(4),(5),(6),(k j)$ for $k=1,2$ and $j=1, \ldots, h\}$ \\
\hline$U^{*}$ & Set: $\{(3),(k j)$ for $k=1,2$ and $j=1, \ldots, h\}$ \\
\hline$S$ & Set: $\{1,2, \ldots, r+1\}, r+1$ is the number of regions (including foreign) \\
\hline$S^{*}$ & Set: $\{1,2, \ldots, r\}, r$ is the number of domestic regions \\
\hline
\end{tabular}

Received: 1 March 2016 Accepted: 20 September 2016

Published online: 13 October 2016

\section{References}

Agénor PR, Izquierdo A, Jensen HT (2007) Adjustment policies, poverty, and unemployment: the IMMPA framework. Blackwell Publishing, Oxford

Álvarez-Martínez MT, Lahr ML (2013). Toward Frameshifting: a discussion of advances in econometric +10 modeling. Unpublished paper presented in at the 2013 conference of the association of University Business and Economic Research, Richmond, Virginia. October 12-15

Anselin L (1999) Interactive techniques and exploratory spatial data analysis. In: Longley PA, Goodchild MF, Maguire DJ, Rhind DW (eds) Geographic information system: principles, techniques, management and applications. Wiley, New York, pp 251-264

Aroca PA, Guo D, Hewings GJD (2008) Spatial convergence in China, 1952-1999. In: Wan G (ed) Inequality and growth in Modern China. Oxford University Press, Oxford, pp 125-143

Dixon PB, Parmenter BR (1996) Computable general equilibrium modelling for policy analysis and forecasting. In: Amman HM, Kendrick DA, Rust J (eds) Handbook of computational economics, vol 1, 1st edn. Elsevier, Amsterdam, pp 3-85

Eby Konan D, Maskus K (1996) A computable general equilibrium analysis of Egyptian trade liberalization scenarios. World Bank working paper no. 97-1, August

Felkner J, Wilson A, Blankenspoor B (2012) Accessibility and transport costs in Egypt: an empirical analysis. In: Reshaping Egypt's economic geography, vol 2. World Bank, Washington, DC

Fujita M, Krugman P (2004) The new economic geography: past, present and the future. Pap Reg Sci 83:139-164 
Giesecke JA, Madden JR (2013) Regional computable general equilibrium modeling. In: Dixon PB, Jorgenson DW (eds) Handbook of computable general equilibrium modeling. Elsevier, Amsterdam, pp 379-475

Haddad EA (1999) Regional inequality and structural changes: lessons from the Brazilian experience. Ashgate, Aldershot Haddad EA (2014a) Spatial perspectives of increasing freeness of trade in Lebanon. Ann Reg Sci. doi:10.1007/ s00168-014-0615-3

Haddad EA (2014b) Trade and Interdependence in Lebanon: an interregional input-output perspective. J Dev Econ Polic 16:5-45

Haddad EA, Hewings GJD (2005) Market imperfections in a spatial economy: some experimental results. Q Rev Econ Finance 45:476-496

Haddad EA, Hewings GJD (2007) Analytically important transportation links: a field of influence approach to CGE models. Rev Bras Estudos Regionais Urbanos 1:63-84

Haddad EA, Barufi AMB, Costa SM (2011a) Regional integration in Colombia: a spatial CGE application. Sci Reg Ital J Reg Sci 10:3-28

Haddad EA, Perobelli FS, Domingues EP, Aguiar M (2011b) Assessing the ex ante economic impacts of transportation infrastructure policies in Brazil. J Dev Eff 3:44-61

Hendy R, Zaki C (2013) Assessing the effects of trade liberalization on wage inequalities in Egypt: a microsimulation analysis. Int Trade J 27(1):63-104

Hu B, McAleer M (2004) Input-output structure and growth in China. Math Comput Simul 64:193-202

Lahr ML (2001) Reconciling domestication techniques, the notion of re-exports, and some comments on regional accounting. Econ Syst Res 13:166-179

Peter MW, Horridge M, Meagher GA, Naqvi F, Parmenter BR (1996) The theoretical structure of MONASH-MRF. Preliminary Working Paper No. OP-85, IMPACT Project, Monash University, Clayton

Sonis M, Hewings GJD (1989) Error and sensitivity input-output analysis: a new approach. In: Miller RE, Polenske KR, Rose AZ (eds) Frontiers of input-output analysis. Oxford University Press, New York

Sonis M, Hewings GJD (1992) Coefficient change in input-output models: theory and applications. Econ Syst Res 4:143-157

Spencer JE (1988) Computable general equilibrium, trade, factor mobility, and the regions. In: Harrigan F, McGregor PG (eds) London: recent advances in regional economic modelling. London papers in regional science 19, London, Pion World Bank (2009) World development report 2009: reshaping economic geography. Washington D.C, USA

World Bank (2012). Reshaping Egypt's economic geography: domestic integration as a development platform. Poverty reduction and economic management department (MNSPR), Middle East and North Africa Region, Document of the World Bank, vol 1 and 2, June

World Road Association (2003) The role of economic and socio-economic models in road management. PIARC Technical Committee on Road Management, Paris

Yang L, Lahr ML (2008) Labor productivity differences in China 1987-1997: an interregional decomposition analysis. Rev Reg Stud 38:319-341

\section{Submit your manuscript to a SpringerOpen ${ }^{\circ}$ journal and benefit from:}

- Convenient online submission

$\checkmark$ Rigorous peer review

- Immediate publication on acceptance

- Open access: articles freely available online

- High visibility within the field

- Retaining the copyright to your article

Submit your next manuscript at $\boldsymbol{\nabla}$ springeropen.com 